\title{
EL ORDEN SUBYACENTE: ARQUITECTURA Y ÓRDENES CLÁSICOS EN ASTURIAS DURANTE LA EDAD MODERNA
}

\author{
Vidal de la Madrid Álvarez \\ Universidad de Oviedo
}

ORCID: https://orcid.org/0000-0001-6608-3417

\section{RESUMEN}

En este artículo se analiza el empleo de los órdenes clásicos en la arquitectura del Principado de Asturias a lo largo de la Edad Moderna. El clasicismo arraigó en la región desde finales del siglo XVI y se mantuvo vigente a lo largo de la mayor parte del siglo XVII relacionado con el trabajo de los maestros cántabros. El barroco decorativo actualizó sus esquemas y los arquitectos ilustrados efectuaron la recuperación de las formas clásicas.

Palabras clave: órdenes clásicos, Juan Bautista Portigiani, Juan del Ribero, Juan de Naveda, Pedro Antonio Menéndez

\section{ABSTRACT}

This study analyses the use of classical orders in the architecture of the Principality of Asturias throughout the Modern Age. Classicism took root in the region in the late 16th century and was pre-eminent for most of the 17th century due to the work of the Cantabrian master architects. Plans were updated with the advent of the decorative Baroque style and the architects of the Age of Enlightenment recovered classical forms.

Keywords: classical orders, Juan Bautista Portigiani, Juan del Ribero, Juan de Naveda, Pedro Antonio Menéndez

En opinión del profesor Ramallo Asensio, sin duda alguna el mejor conocedor de la arquitectura de la Edad Moderna en Asturias, es posible distinguir en ella la existencia de una serie de invariantes que identifican y singularizan estas obras a lo largo del tiempo'. Entre estas constantes creativas figuran la sobriedad ornamental, el empleo de sillería bien escuadrada, que proporciona dignidad a las zonas nobles, y, sobre todo, la preferencia por el clasicismo, que se aprecia en el respeto a las proporciones y en el empleo riguroso de los órdenes. De esta forma pueden explicarse la persistencia del gusto clásico derivado de la escuela vallisoletana hasta el último cuarto del siglo XVII en la obra de los maestros montañeses activos en la región, el escaso impac- to que tuvo el barroco decorativo, prácticamente limitado a la obra de los Menéndez Camina y Francisco de la Riva, o la facilidad de recuperación de las propuestas clasicistas con la llegada del reformismo borbónico en la obra de Pedro Antonio Menéndez. Por otra parte, entre las razones que pudieron contribuir a la continuidad del gusto clásico debemos contemplar el menor coste de unos diseños sobrios y funcionales, que se convirtieron en una solución recurrente para una sociedad con recursos siempre menguados. En cualquier caso, las formas clásicas, que aparecieron en la arquitectura asturiana en la segunda mitad del siglo XVI, actuaron como soporte creativo de las construcciones del Principado a lo largo de toda 


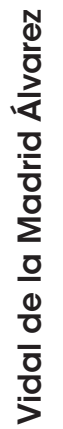

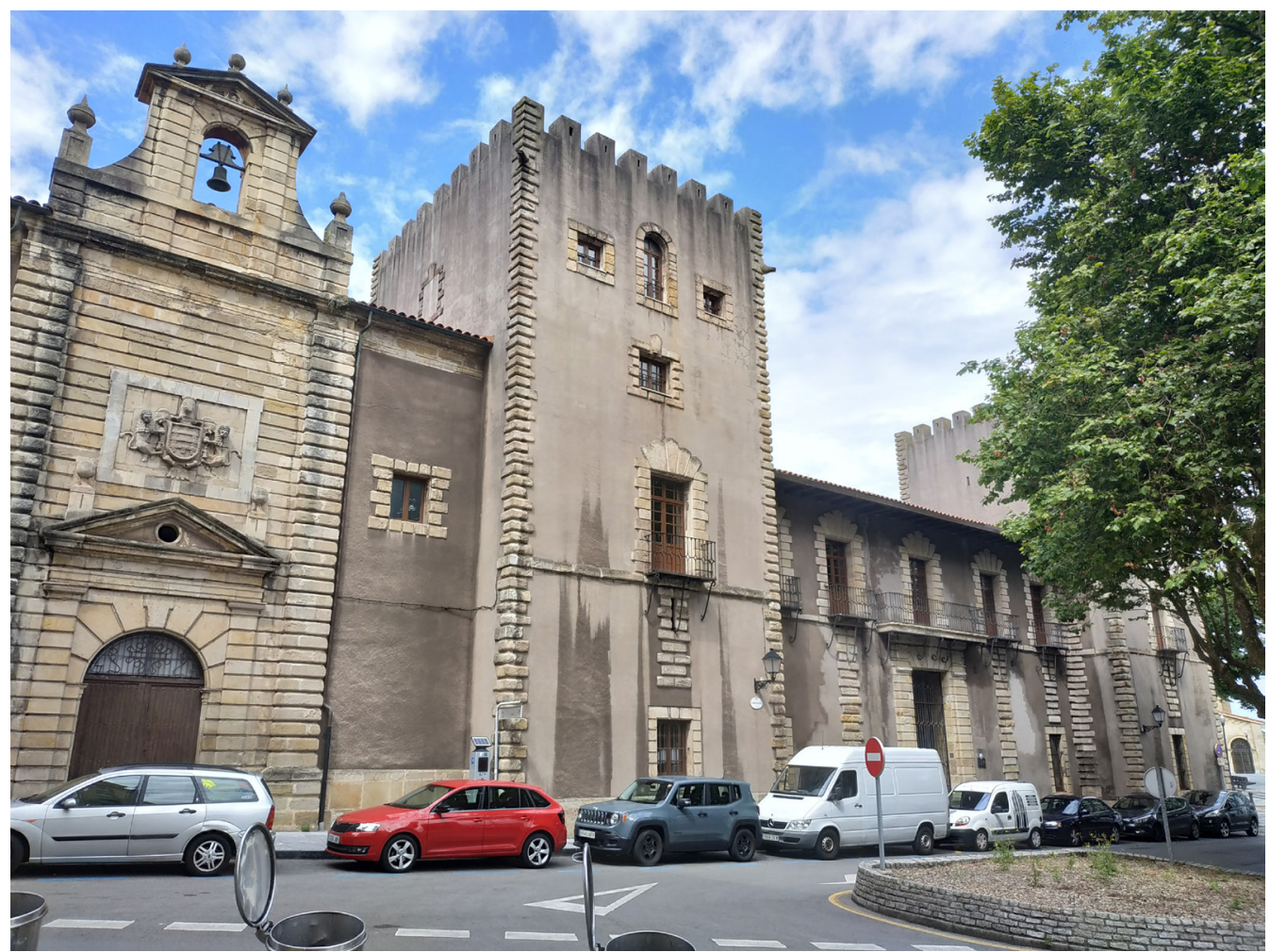

Fig. 1. Casas de Valdés en Gijón (1564), hoy Colegio de Santo Ángel de la Guarda, y capilla de Nuestra Señora de Guadalupe (1625)

la modernidad, proporcionándoles una innegable personalidad artística².

\section{El preludio serliano}

Al iniciarse el último tercio del siglo XVI, Juan de Valdés (†1571), hidalgo y regidor gijonés, a quien el genealogista José Manuel Trelles consideraba una "persona poderosa en aquella villa de Gijón y su territorio" ${ }^{3}$, decidió construir su residencia familiar en la población. En aquel momento gozaba ya de un patrimonio estimable y en 1562 había obtenido facultad real para fundar su mayorazgo, aunque este no se hizo efectivo hasta unos años más tarde ${ }^{4}$. Además, estaba emparentado con Fernando de Valdés Salas (Salas, Asturias, 1483-Madrid, 1568), arzobispo de Sevilla y presidente del Consejo de Castilla5, cuyas fundaciones, así como las iniciativas de sus testamentarios, condicionaron el panorama artístico asturiano de finales del siglo XVI y principios de la centuria siguiente, al favorecer la llegada a la región de algunos de los mejores artífices del momento. Precisamente, uno de esos artistas, el florentino Juan Bautista Portigiani, activo en España al menos entre 1564 y 1574, fue el responsable del diseño de la fachada de las casas de Valdés en el gijonés barrio de Cimadevilla ${ }^{6}$.

En la actualidad, el conjunto de las antiguas casas de Valdés, conocidas también como palacio o torres de Valdés (hoy Colegio de Santo Ángel de la Guarda), se compone de un edificio residencial organizado en torno a un patio porticado y una capilla adosada a su flanco occidental, que presenta la advocación americana de Nuestra Señora de Guadalupe (fig. 1). El empleo del léxico serliano proporciona a toda la obra una apariencia de unidad, aunque el templo fue erigido unos sesenta años más tarde que la vivienda familiar y cada obra responde a un promotor y un arquitecto diferentes? 
En los años sesenta del siglo XVI el arquitecto Juan de Cerecedo el Viejo ( $†$ h. 1568), en aquel momento maestro de la catedral de Oviedo, proporcionó las primeras trazas para la construcción de las casas de Juan Valdés en Gijón:. No obstante, en 1564, una vez iniciados los trabajos, el promotor decidió prescindir del diseño primitivo y encargó un nuevo proyecto al florentino Juan Bautista Portigiani'. Aún se desconocen las razones que puedan justificar la presencia de Portigiani en Asturias en estos años y tan sólo esta obra no parece motivo suficiente. Resulta razonable considerar que hubiera acudido al Principado para atender otros encargos, tal vez relacionados con el mecenazgo de Fernando de Valdés Salas, con quien aparece vinculado algún tiempo después.

En cualquier caso, el origen de este maestro todavía no está claro, pese a que tradicionalmente se le considera descendiente del escultor florentino Pagno di Lapo Portigiani, y, según lo vamos conociendo, su personalidad artística resulta cada vez más atractiva. Acerca de su obra en la península itálica tenemos muy pocos datos y tan sólo se le relaciona con dos estatuas de un sepulcro en la iglesia de la abadía de Montecasino (Lacio) realizadas en $1558^{10}$. Ya en España, su primer trabajo documentado fue precisamente el palacio de Valdés (1564), pero tres años después, en 1567, contrató con Hernando de Valdés, canónigo de la catedral de Oviedo, en nombre de su tío Fernando de Valdés, arzobispo de Sevilla, la factura de un retablo en la villa de Salas, probablemente destinado a la colegiata de Santa María la Mayor, fundada por los progenitores del arzobispo en 1549 y donde hoy se encuentra su mausoleo de alabastro (1576-1586), realizado por el escultor de corte Pompeyo Leoni (h. 1533-Madrid, 1608)"1. Dos años más tarde, en 1569, Portigiani apareció de nuevo en Oviedo contratando la pintura y la instalación de un retablo de terracota policromada que acababa de realizar para la ermita de Nuestra Señora de El Valle en Pravia (Asturias) y que aún se conserva'12. En ese momento manifestó la necesidad de desplazarse a Castilla para atender sus negocios y en 1570 se encontraba ya en la corte trabajando como aparejador de Pompeyo Leoni en las esculturas y arcos que éste había diseñado para realzar la entrada triunfal de la reina Ana de Austria en Madrid ${ }^{13}$. No

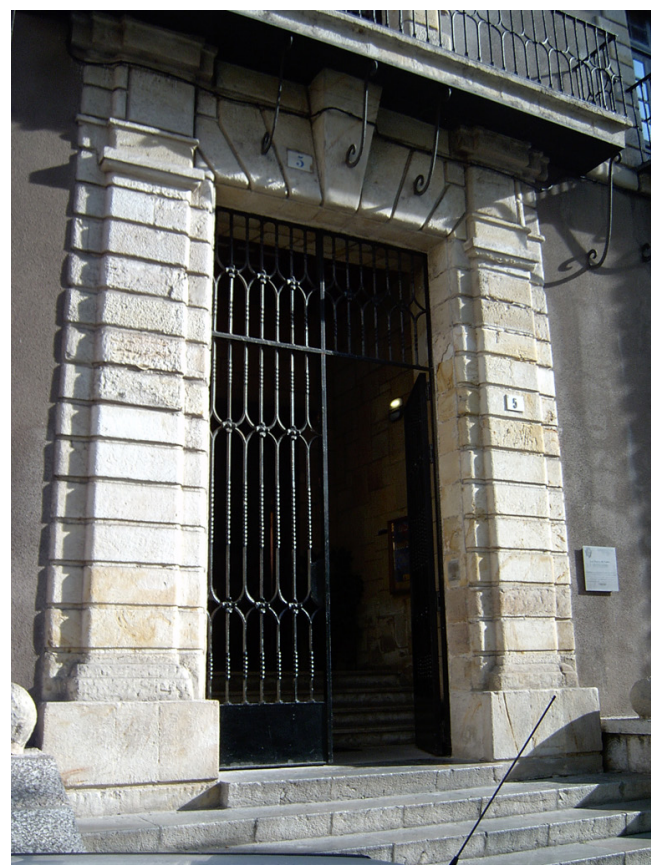

Fig. 2. Casas de Valdés en Gijón (1564), hoy Colegio de Santo Ángel de la Guarda. Entrada principal

obstante, su intervención en estos festejos no se limitó a actuar como sobrestante de Leoni, sino que asumió también la construcción de un castillo de madera con almenas y torre del homenaje y ocho galeras, que debían navegar en un estanque frente a la fortaleza para protagonizar un combate naval'14. Los años siguientes Portigiani aparece avecindado en Madrid, desde donde se desplazó a Briviesca (1572) para la tasación de un retablo y a Toledo (1574) para intervenir en la tasación de los facistoles realizados por Nicolás Vergara el Mozo para la catedral, que finalmente resolvió Pompeyo Leoni15. Por último, en 1574 Portigiani manifestó interés en la explotación de una mina de plata en el término manchego de Villamayor de Calatrava ${ }^{16}$. En fin, se trata, sin duda, de un autor muy cualificado, conocedor del arte italiano del momento, bien relacionado en los círculos cortesanos, como demuestra su proximidad con Leoni, y capaz de desenvolverse con eficacia en la arquitectura, la escultura o la orfebrería.

El palacio responde a un modelo recurrente en la arquitectura castellana, que toma su carácter defensivo de la fortaleza o del alcázar y experi- 
menta un proceso de armonización o regularización por influjo de los ejemplos italianos ${ }^{17}$. El conjunto se organiza por medio de cuatro crujías dispuestas en torno a un patio porticado con columnas toscanas asentadas sobre un murete bajo que recorre todas las galerías. Portigiani llegó a la obra con los trabajos ya iniciados bajo la dirección del maestro Juan Pérez de Helguera y según las trazas elaboradas por Juan de Cerecedo el Viejo. La presencia, probablemente inesperada, de un arquitecto florentino en Gijón despertó, sin duda, el interés del promotor por contar con una residencia a la moda, distante de la apariencia tardogótica habitual en las viviendas asturianas por aquellos años y en sintonía con las corrientes artísticas cortesanas. En consecuencia, Valdés decidió abandonar la propuesta de Cerecedo y encargó al italiano unas nuevas trazas para sus casas, aunque, en realidad, las condiciones de obra que conocemos no van más allá del diseño de la fachada'18.

Esta fachada se configura en tres piezas, tramo apaisado y dos torres esquineras más adelantadas. Las torres se rematan con almenas conservando la idea de fortaleza medieval como un recurso de prestigio alusivo a la antigüedad del linaje. Se trabaja, por tanto, en la elaboración de un simulacro de castillo, que justifica también el carácter cerrado de la planta baja, así como la utilización de unas saeteras descritas con gran precisión en las condiciones de obra. En este planteamiento el orden rústico se convierte en un recurso muy apropiado, pues no sólo alude al carácter lejanamente defensivo de la construcción, sino que actúa como un factor de ennoblecimiento y modernidad, vinculado tanto a la erudición arquitectónica, como a la novedad artística.

Asimismo, el almohadillado se emplea como una herramienta de ordenación y estructuración del muro, integrando las saeteras y prolongándose en vertical desde los voladizos de los balcones hasta el suelo, tanto en el cuerpo central como en las torres, donde también recorre las esquinas (fig. 2). Este mismo aparejo rústico configura una línea de imposta que separa la planta baja, cerrada y defensiva, del piso principal, de concepción abierta y palaciega, y se extiende incluso en ambas torres, favoreciendo la unidad de los elementos. Por su parte, las enmarcaciones de balcones y ventanas se guarnecen con almohadillados de volumen decreciente y los tres vanos superiores de las torres sugieren el trazado de una serliana ${ }^{19}$. En cuanto a la puerta principal, se compone también en modo rústico con dos pilastras toscanas flanqueando un acceso adintelado, siguiendo un esquema que Portigiani parece haber tomado de una de las láminas del Libro Quarto de Architectura de Sebastián Serlio (Bolonia, 1475-Fontainebleau, 1554)20, que en la edición española (1563) de Francisco Villalpando aparece en el folio XII, aunque sustituyendo el arco original por un dintel.

Aunque desconozcamos su biblioteca y su figura esté pendiente aún de nuevas aportaciones, no cabe duda de que Juan Bautista Portigiani atesoraba una excelente formación técnica, que le permitía colaborar con los principales artistas del momento y practicar diversas artes, y un buen conocimiento de la teoría arquitectónica del momento. La adopción del léxico rústico teorizado por Sebastián Serlio para el diseño de la fachada de las casas de Valdés parece tener que ver con una perfecta comprensión de las propuestas del tratadista boloñés, aunque pudo haber conocido directamente alguno de los palacios romanos que muestran aspectos más o menos próximos a la obra gijonesa, como el Adimari Salviati (h. 1520) o el Maccarani Stati (1522-23). Por otro lado, en esos años ya se había asentado con fuerza en España el influjo de Serlio y, de forma singular, el empleo del orden rústico, que, según Fernando Marías, constituyó «la característica más acentuada del serlianismo de mediados del siglo XVI español»21. En consecuencia, Portigiani parece haber combinado su conocimiento directo de las obras romanas con su manejo del tratado de Serlio y su familiaridad con los trabajos ya realizados en la península -de forma particular la obra toledana de Alonso de Covarrubias (Torrijos, Toledo 1488-Toledo, 1570)- para proporcionar a Juan de Valdés una vivienda moderna, con aspectos de erudición y el prestigio inherente a su apariencia de fortaleza.

En cuanto a la capilla, se trata de un encargo de Fernando de Valdés, que contrató la obra con el maestro Pedro de Cubas de la Huerta en $1625^{22}$. Fernando de Valdés era nieto del promotor del palacio e hijo del almirante Pedro de 
Valdés, quien desempeñó relevantes cargos militares en la armada y en los territorios americanos, pues, entre otras acciones, participó en la conquista de La Florida y fue gobernador y capitán general de la isla de Cuba. Además, tanto Fernando de Valdés como su esposa, Luisa de Valdés Miranda, declararon algún tiempo más tarde que la erección del templo se debió a la devoción del almirante por la Virgen de Guadalupe, adquirida, sin duda, en sus años de servicio en América ${ }^{23}$.

Respecto al arquitecto escogido para erigir la capilla, el montañés Pedro de Cubas, apenas tiene obra conocida, salvo su trabajo durante esos años en las reformas del puerto de Gijón y la construcción de las casas del arcediano Toribio Vigil de Quiñones en la villa en $1625^{24}$. No contaba, desde luego, con la proyección profesional del maestro florentino, pero demostró una buena formación teórica y logró armonizar perfectamente las dos edificaciones que integran el conjunto de las casas de Valdés.

Su propuesta, probablemente influida por la voluntad de los promotores, se fundamentaba en lograr una adecuada concordancia estilística con la fachada concebida por Portigiani, lo cual supuso acudir de nuevo al repertorio del orden rústico divulgado por Serlio. Sin embargo, el tiempo transcurrido y la práctica habitual del maestro montañés, acostumbrado a manejar un sobrio léxico clasicista derivado de la escuela vallisoletana y, en último término, de Juan de Herrera (Movellán, Cantabria, 1530-Madrid, 1597), exigió combinar con desenvoltura ambos lenguajes evitando las estridencias.

De esta forma, en el interior se optó por un modelo próximo a las capillas de esa época, en la línea de lo realizado en la región por Juan de Naveda (San Mamés de Aras, Cantabria, 1590León, 1638) -bóveda vaída, pilastras, nichos bajo frontón- y en el exterior se combinó el orden rústico con algunos recursos más castizos, como las esferas o la espadaña. En este último caso se atendió a una exigencia de las condiciones del contrato, donde se toma como modelo el campanario de la capilla de Nuestra Señora de la Concepción en Villaviciosa, que había sido edificada en 1623, según proyecto de Juan de Naveda ${ }^{25}$. En cuanto al orden rústico, Cubas emplazó el acceso al templo sobre una gran pantalla almohadillada flanqueada por dos grandes fajas y compuso la portada combinando dos láminas del Libro Quarto de Architectura de Serlio, según demostró en su momento Ramallo Asensio ${ }^{26}$, una de las cuales ya había servido como punto de partida para la puerta del palacio. Además, las pequeñas saeteras de la vivienda se transformaron en grandes ventanales abocinados para iluminar el retablo y las esquinas de la construcción recuperaron el paramento almohadillado de la vivienda. Pese a este protagonismo del aparejo rústico, en la capilla todo es más plano, rígido y geométrico, y se atenúa la plasticidad que Portigiani había logrado en la vivienda.

El conjunto supuso, por tanto, la introducción del gusto serliano en la región en sintonía con las obras que se estaban realizando en el reino y se convirtió inmediatamente en un modelo arquitectónico, que extendió su influencia, al menos, hasta finales del siglo XVII27.

\section{El primer clasicismo}

La presencia fugaz de Portigiani en Gijón proporcionó el primer ejemplo de arquitectura clasicista de inspiración italiana en Asturias, aunque, como hemos visto, se trató de una solución cosmética para modernizar una estructura iniciada con planteamientos creativos más retardatarios. Tan sólo unos años más tarde se confirmó la penetración del nuevo estilo en la región, que se efectuó, fundamentalmente, a través de dos caminos: el mecenazgo del arzobispo Fernando de Valdés Salas y las reformas emprendidas por las órdenes religiosas ${ }^{28}$.

No cabe duda de que el edificio de la Universidad de Oviedo tuvo una singular relevancia en la introducción del gusto clásico en la región, pero su ejecución fue un proceso largo y accidentado y su autoría aún sigue siendo objeto de debate ${ }^{29}$ (fig. 3). La fundación de este centro universitario se debió al mecenazgo de Fernando de Valdés Salas, que había sido obispo de Elna (1529), Orense (1530), Oviedo (1532), León (1539) y Sigüenza (1540), además de presidente del Consejo de Castilla (1539), inquisidor general (1547-1566) y arzobispo de Sevilla (1546-†1568) ${ }^{30}$. Durante el desempeño de estos cargos logró reunir una considerable fortuna, que dedicó de forma especial a la fundación de establecimientos de enseñanza 


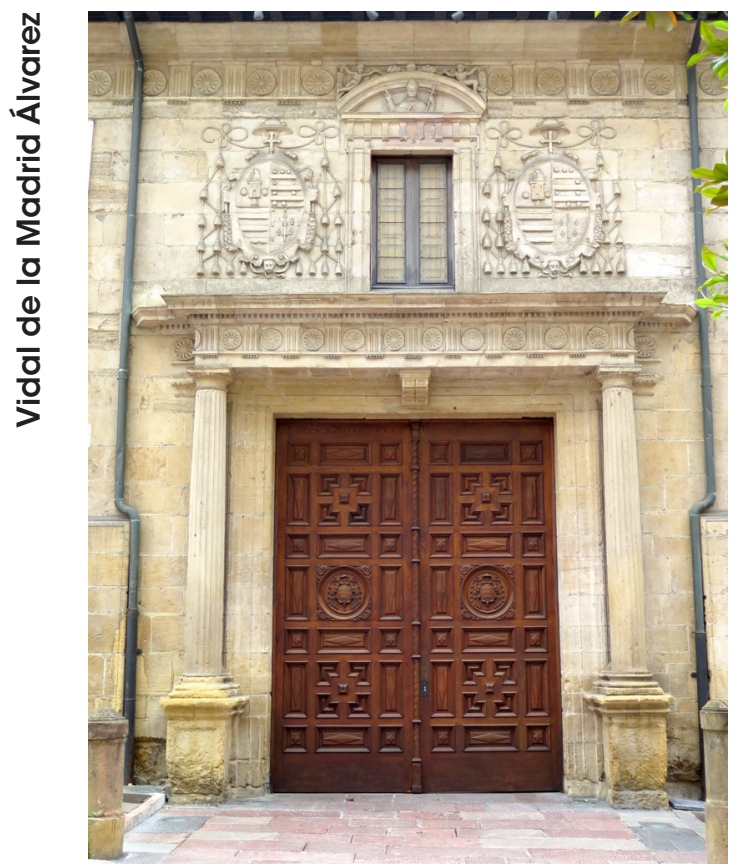

Fig. 3. Universidad de Oviedo (1574-1598). Entrada principal

como el Colegio de San Pelayo en Salamanca, y, en Oviedo, el Colegio de San Gregorio, el Colegio de Huérfanas Recoletas y la Universidad ${ }^{31}$. En lo que atañe al centro universitario, el 28 de noviembre de 1568 Valdés donó 11.500 ducados para la construcción de su edificio, que incluían 1.500 ducados para la casa de doncellas, y destinó 750.000 maravedíes como renta anual para su funcionamiento ${ }^{32}$. No obstante, la fundación universitaria fue una iniciativa tardía, concretada tan sólo unos días antes de su muerte, y hubo de confiarse forzosamente al oscilante compromiso de sus testamentarios, que tardaron cuarenta años en materializarla.

La obra del edificio universitario fue contratada el 12 de junio de 1574 por 20.000 ducados con el maestro Rodrigo Gil de Hontañón (Rascafría, Madrid, 1500-Segovia, 1577), quien, unos días más tarde, el 19 de junio, apoderó a Juan del Ribero Rada (Rada, Cantabria, h. 1540-Salamanca, 1600) para que actuase como aparejador en su nombre ${ }^{33}$. Es bien conocida la relación profesional establecida entre ambos arquitectos, que adquirió un especial relieve en los trabajos del palacio de los Guzmanes en León, donde se documenta a Ribero en 1564 y donde, al igual que sucedió en la Universidad de Oviedo, este maestro actuó como aparejador de una obra trazada por Gil. Además, la atribución a Ribero de algunas zonas significativas del palacio, como las ventanas angulares de la torre sudeste o la portada de la calle del Cid, apoyándose en su carácter clásico y su proximidad con las propuestas de Serlio, demuestra la capacidad del maestro montañés para actuar con cierta desenvoltura en los proyectos de Gil y actualizar una idea arquitectónica más retardataria ${ }^{34}$.

En Oviedo, los trabajos avanzaron con dificultad debido al desinterés de los testamentarios del arzobispo, que demoraban los pagos y provocaban frecuentes reclamaciones, tanto de Gil como de Ribero o del maestro Diego Vélez († h. 1600) ${ }^{35}$, quien actuó como sobrestante a pie de obra. Estos contratiempos culminaron en junio de 1578 , tan sólo un año después del fallecimiento de Rodrigo Gil, cuando Juan Osorio de Valdés, hijo natural del arzobispo, acudió a la región comisionado por los testamentarios para supervisar los trabajos y mostró su desacuerdo con el proyecto. Osorio, haciendo uso de sus atribuciones, ordenó modificar aquellos aspectos que lo contrariaban y elaborar unas nuevas trazas acomodadas a su particular concepción del edificio, es decir, una obra "a su gusto e contento" ${ }^{36}$. La resistencia de Ribero a variar las trazas de Gil provocó su encarcelamiento y el traspaso de la obra al sobrestante Diego Vélez ese mismo mes. Este maestro realizó los cambios en las trazas originales que exigía Osorio, derribó todo lo ya construido que obstaculizase el nuevo plan y se aplicó a ejecutarlo. Sin embargo, en enero de 1584 Vélez acabó también en prisión, pues los testamentarios consideraban que, a causa de los incumplimientos del maestro, la obra no había avanzado como se esperaba, pues ya se habían consumido 17.000 ducados del presupuesto y el patio aún no se había edificado. El conflicto con Vélez se saldó con el retorno de Ribero, que se ocupó de dirigir los trabajos hasta su conclusión en la última década del siglo ${ }^{37}$.

Las distintas alternativas al frente de la obra, así como la resuelta intervención de Juan Osorio, difuminaron la autoría del conjunto, pese a la insistencia de Ribero en respetar las trazas de Rodrigo Gil38. Éste, según las condiciones de obra 
publicadas por Faya Díaz ${ }^{39}$, concibió un edificio compuesto de cuatro crujías dispuestas en torno a un patio cuadrangular porticado (fig. 4). En esta idea, la galería oriental, donde se ubicaba la capilla, y la septentrional, donde se abría la portada principal, tendrían dos plantas, mientras que la occidental y la meridional tan sólo una. En cuanto a los órdenes empleados, las columnas del patio serían de orden dórico con basa toscana, tanto en la planta baja, como en el primer piso, y también proponía este orden para la puerta principal, donde se esbozó un diseño muy similar al actual ${ }^{40}$. Las trazas de Gil se siguieron puntualmente hasta el reconocimiento efectuado por Osorio en 1578. El hijo del arzobispo argumentó muchos defectos en el planteamiento del arquitecto, que por entonces ya había fallecido y no podía contradecirle. Sus reparos eran, esencialmente, de carácter funcional, aunque también introdujo detalles de carácter estético, que nos advierten de su interés por actualizar el diseño ${ }^{41}$. Entre los reparos funcionales destaca el cambio de ubicación de la capilla, la sacristía y la escalera principal, lo cual supuso la demolición de una gran parte del recinto, pues estas zonas ya se encontraban muy avanzadas. En la nueva capilla se situó una fachada de orden dórico similar a la portada principal y en la cabecera del templo, a ambos lados del retablo estaba previsto abrir sendas ventanas de orden rústico ${ }^{42}$. Además, se dispuso una entrada en el lienzo oriental para facilitar la llegada de los universitarios desde la ciudad. Este acceso, aún conservado, es una puerta adintelada con sus dovelas almohadilladas inspirada en un diseño rústico similar reproducido en una de las láminas del Libro Quarto de Architectura de Serlio, que en la edición española de Villalpando aparece en el folio XII. Todas estas reformas fueron plasmadas en unas nuevas trazas por Diego Vélez, que debe ser considerado el responsable de la introducción de estos aspectos serlianos en el conjunto ${ }^{43}$.

Finalmente, el desplazamiento de Vélez por Ribero se efectuó cuando aún no había realizado el patio. Rodrigo Gil había planteado unas galerías sobrias, con ausencia de ornato, y había previsto el empleo de orden toscano, tanto para la planta baja, como para el primer piso de las pandas oriental y septentrional, las únicas que contarían con dos alturas. Pese a ello, el orden empleado finalmente en el primer piso fue el jó-

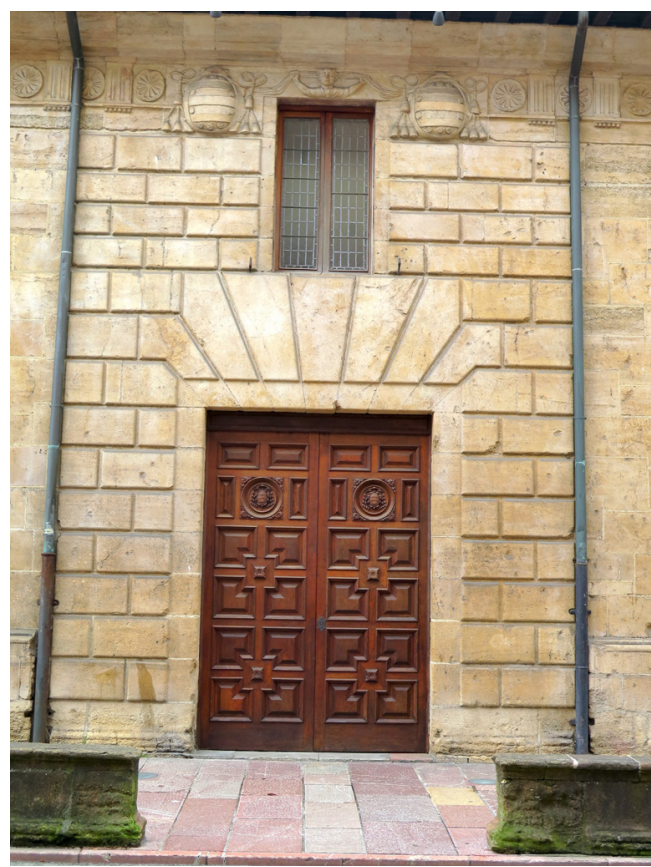

Fig. 4. Universidad de Oviedo (1574-1598). Entrada oriental

nico, garantizando la superposición de órdenes y profundizando en la modernización clasicista del conjunto, que debe atribuirse al maestro de Rada. No obstante, el ritmo doble de las columnas del piso superior, dispuestas tanto sobre la columna inferior como sobre la clave del arco, es un arcaísmo evidente, remite a las soluciones habituales de los claustros tardogóticos y tal vez responda a la cadencia concebida inicialmente por Gil, que Ribero no quiso modificar ${ }^{44}$.

En cuanto a la puerta principal, podrían plantearse algunas dudas, pero responde esencialmente al diseño de Gil (fig. 5). Es un acceso adintelado flanqueado por dos columnas dóricas estriadas con capitel de ovas sosteniendo un entablamento con friso de rosetas y triglifos, que se extiende por el perímetro de todo el conjunto proporcionándole unidad. Sobre él descansan dos escudos del fundador flanqueando una ventana tomada de una lámina del Libro Quarto de Architectura de Serlio, que en la edición de Villalpando aparece en el folio XXVII y que en Oviedo sustituye el frontón triangular de la estampa por el curvo. Esta ventana se remata con figuras de jóvenes desnudos sosteniendo ristras de frutas de 


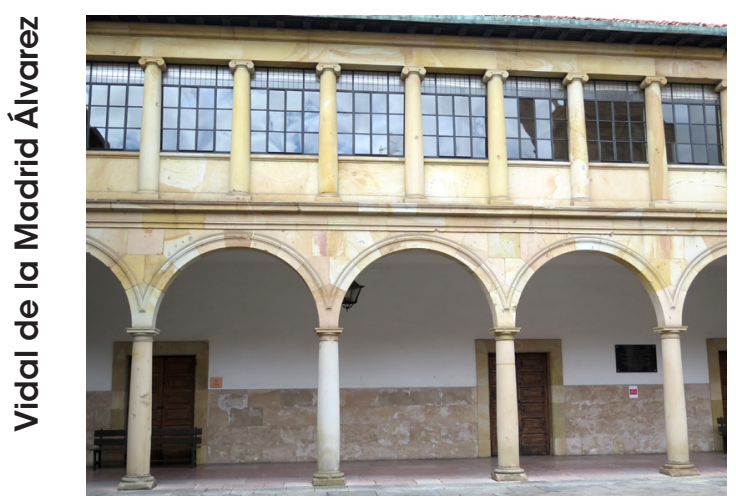

Fig. 5. Universidad de Oviedo (1574-1598). Patio

inspiración serliana y con el busto de un papa con tiara bendiciendo en el tímpano -tal vez quiera ser el pontífice Gregorio XIII (1572-†1585), que había concedido la bula fundacional del centro el 15 de octubre de 1574-. Pastor Criado ya ha comentado la proximidad de estos capiteles dóricos con los de la portada prioral de San Isidoro de León (1581-82), obra segura de Ribero, que se inspiró en un grabado de De Architectura de Vitrubio ${ }^{45}$, pero en Oviedo parece inspirarse en la versión de Vignola, especialmente en la decoración del anillo bajo el equino de ovas, y las rosetas de las metopas remiten a la propuesta dórica de Serlio. La composición general, por su parte, estaría próxima a su diseño de la portada de la portería del convento de San Esteban de Salamanca (1590-91), también adintelada y con columnas exentas e inspirada, según Rodríguez G. de Ceballos y Casaseca, en la puerta de la Cancillería de Roma reproducida, a su vez, en la Regla de Viñola ${ }^{46}$. Por todo ello, es posible que Ribero hubiese seguido el diseño de Gil, pero con alguna aportación personal.

Según hemos visto, el accidentado proceso de ejecución de la sede primitiva de la Universidad de Oviedo ha sido la causa de constantes dudas e indecisiones a la hora de adjudicar la autoría de un edificio clave para la irrupción del clasicismo en el territorio asturiano. El proyecto original de Rodrigo Gil fue modificado por unas nuevas trazas parciales de Diego Vélez e interpretado, más o menos respetuosamente, por Juan del Ribero para alumbrar una propuesta arquitectónica de autoría múltiple, que se convirtió inmediata- mente en prototipo arquitectónico regional. En consecuencia, el empleo de los órdenes se fue adaptando a las necesidades de cada momento del proceso edificatorio y no parece responder a una sola idea rectora, más allá del común interés por lograr una obra moderna y comprometida con el nuevo gusto clásico.

La difusión del modelo de patio clasicista desarrollado por Gil y Ribero en la universidad ovetense corrió a cargo del maestro montañés Domingo de Mortera (Omoño, Cantabria, 1560-Oviedo, $1608)^{47}$. Este maestro se había formado con Diego Vélez, trabajó para Juan del Ribero en la obra universitaria y poseía una interesante biblioteca, en la que figuraban entre otros, los libros de Moya, Serlio en la edición española de Villalpando, Viñola, Palladio y Alberti48. Tras intervenir en los trabajos del patio universitario, dio las trazas para los claustros monásticos de San Francisco del Monte en Avilés y Santa María en Belmonte de Miranda, donde resulta evidente la huella de esa obra. En Avilés tan sólo se conservan dos crujías del claustro clasicista, que fue construido por el montañés Gonzalo Güemes Bracamonte siguiendo la traza y condiciones de Mortera entre los años 1599 y 160449. En origen tenía planta cuadrangular y se componía de cuatro crujías articuladas en dos niveles. El inferior presenta arcadas de medio punto dispuestas sobre columnas toscanas que se apoyan en un podio corrido y el superior se compone de columnas del mismo orden dispuestas a ritmo doble sosteniendo una estructura adintelada. El esquema es semejante al patio universitario, manteniendo la duplicación del ritmo en el primer piso y la máxima austeridad ornamental, aunque prescinde de la superposición de órdenes y el canon de las columnas inferiores pierde esbeltez al descansar sobre un podio. El claustro del monasterio cisterciense de Belmonte, por su parte, no ha llegado hasta nosotros, pero podemos hacernos una idea gracias a una estampa de Francisco Javier Parcerisa (Barcelona, 1803-1875) publicada en Recuerdos y Bellezas de España (1855)50. Su erección fue rematada en 1598 con arreglo a las trazas elaboradas por Domingo de Mortera51. La lámina de Parcerisa muestra un edificación similar a la avilesina, con dos plantas de columnas de orden toscano, doble ritmo en el primer piso y arquería sobre podio en la planta inferior. En ambos ca- 
sos, la ausencia de superposición de órdenes nos llevaría al proyecto inicial de Rodrigo Gil para el patio universitario.

Por su parte, el arquitecto Juan del Ribero también contribuyó decisivamente a la difusión del gusto clásico a través de sus proyectos para la reforma de los monasterios vinculados a la Congregación de San Benito52. Según la profesora Campos Sánchez-Bordona, Ribero logró desarrollar un prototipo arquitectónico adaptado a las necesidades de la Congregación vallisoletana, que se fue adoptando en todas las casas vinculadas a la reforma de la observancia. Su propuesta se caracterizaba por una distribución de espacios fundamentada en una eficiente integración de funciones, en una moderna sistematización del trabajo, que permitía al maestro suministrar las trazas y asignar la ejecución a sobrestantes de su confianza, y en la adopción del léxico clasicista, que proporcionaba coherencia y racionalidad a todo el conjunto ${ }^{53}$. En Asturias su intervención está documentada en los monasterios de San Vicente de Oviedo, donde culmina su templo, y San Juan Bautista de Corias, donde diseña el claustro y se le atribuyen las trazas de la iglesia.

El monasterio de San Vicente se incorporó a la Congregación de Castilla en $1517^{54}$. Es posible que a partir de este momento se iniciase un ambicioso programa de reformas y expansión del conjunto que se prolongó hasta el siglo siguiente ${ }^{55}$ (fig. 6). Las obras se iniciaron en el claustro y continuaron por el templo, cuyo proyecto inicial fue ideado por Juan de Cerecedo el Viejo (th. 1568) y a su muerte fue proseguido por su sobrino, Juan de Cerecedo el Joven (†1580), que se encontraba trabajando en el monasterio en $1571^{56}$. Sin embargo, parece que la actividad se detuvo en una fecha incierta entre ese año y 1587, cuando el abad fray Pedro de Agüero decidió buscar un nuevo maestro para concluir las obras de la iglesia, dando a entender que llevaban algún tiempo abandonadas y era necesario cubrir el templo cuanto antes para no perder lo ya edificado. Con este fin, en mayo de 1587 Agüero contrató a Juan del Ribero en Valladolid, probablemente aconsejado por los responsables de la Congregación, pues se había convertido en su arquitecto de confianza y, entre otros proyectos, había realizado la traza universal del monasterio
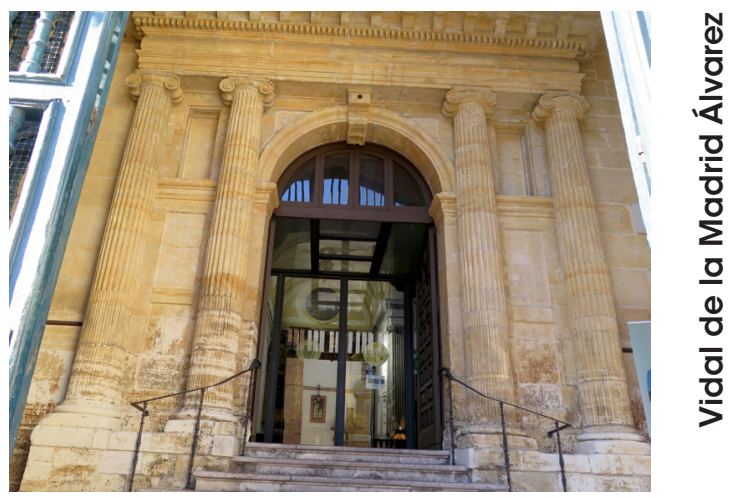

Fig. 6. Iglesia del monasterio de San Vicente (1587) en Oviedo. Portada

de San Benito de Valladolid (h. 1584), que lideraba la observancia y se encontraba en proceso de reconstrucción general bajo unos planteamientos absolutamente clasicistas ${ }^{57}$.

Cuando contrató con el abad Agüero, Ribero era ya un arquitecto respetado profesionalmente, con una magnífica formación teórica, que incluso le permitió redactar una traducción al español del tratado de Palladio, un buen conocimiento de las novedades arquitectónicas italianas, aunque, hasta el momento, nunca haya podido demostrarse que hubiera estado en la península itálica, $y$, sobre todo, un compromiso con el clasicismo derivado de su asimilación de las propuestas de Juan Bautista de Toledo (h. 1515-Madrid, 1567) y Juan de Herrera. En Oviedo se enfrentó a un proyecto ya iniciado que actualizó aprovechando gran parte de la obra realizada y utilizando los órdenes como ropaje modernizador clasicista. Es muy posible que, según supone Ramallo Asensio, la planta tradicional de cruz inscrita con capillas entre contrafuertes estuviese elevada tan sólo hasta las líneas de imposta, pues el abad afirma que en ese momento faltaban por hacerse las bóvedas del templo ${ }^{58}$. En consecuencia, Ribero cerró las capillas con bóvedas de cañón y dispuso esbeltas pilastras estriadas de orden jónico sobre los contrafuertes, modulando el ritmo de los muros de la nave. Sobre las pilastras colocó un entablamento corrido con su arquitrabe de tres fajas, friso liso convexo y cornisa con dentículos (fig. 7). Tanto el capitel como el entablamento reproducen con fidelidad el modelo propuesto por Serlio para el orden jónico en su Libro Quarto 


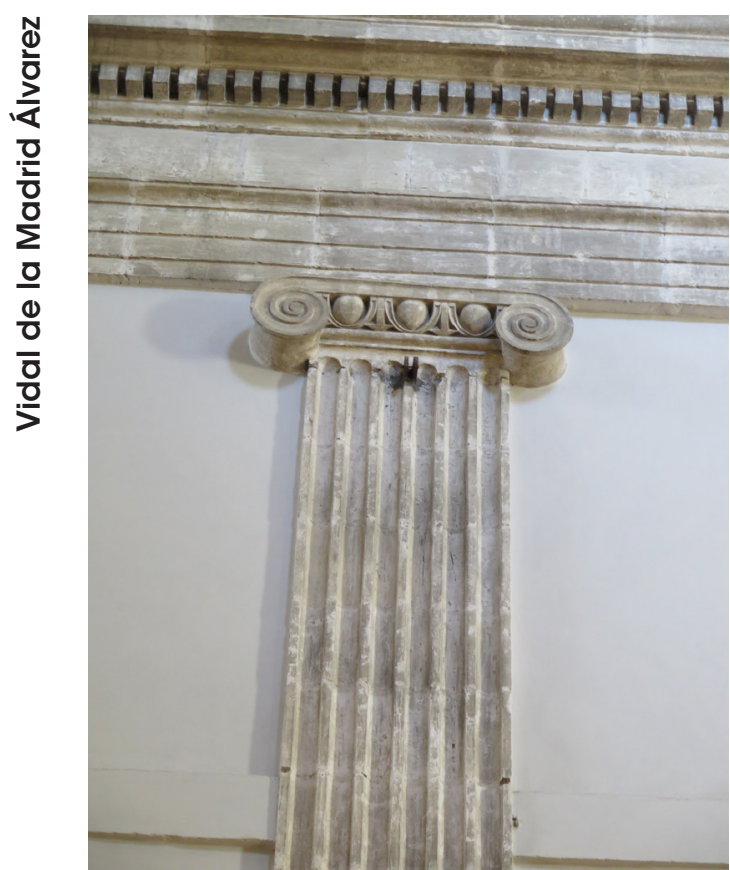

Fig. 7. Iglesia del monasterio de San Vicente (1587) en Oviedo. Detalle de una pilastra de la nave

de Architectura, que aparece en la lámina XI de la edición española de Villalpando. Este mismo esquema se extendió a las puertas interiores, con friso convexo y cornisa con dentículos, y, de forma especial, a la portada interior del templo, garantizando la unidad de toda la estructura bajo los presupuestos artísticos del orden jónico serliano.

La portada de San Vicente, sin duda una de las piezas más acertadas del arquitecto, emplea el modelo de arco triunfal de inspiración clásica con acceso de medio punto flanqueado por dos columnas jónicas a cada lado. Estas columnas, al igual que las pilastras de la nave, presentan fuste estriado y sostienen un entablamento con friso liso convexo, dentículos y cornisa sobre ménsulas. La estructura se remata con un frontón curvo que acoge un nicho o ventana ciega en el centro y esferas dispuestas a plomo sobre los soportes. El espacio entre las columnas se encuentra ocupado por recuadros de escaso resalte en el nivel inferior, que se transforman en nichos de cierta profundidad sobre la línea de imposta. Esta portada de San Vicente se encuentra estrechamente relacionada con la fachada prioral de San Isidoro de León (1580-83), también concebida por Ribero, y ambas se inspiran en láminas de portadas serlianas reproducidas en el Libro Quarto de Architectura, aunque sin remitirse a un modelo concreto $^{59}$. En León, Ribero optó por el orden dórico y un friso clásico de triglifos y bucráneos, pero el esquema esencial apenas varía y demuestra hasta qué punto el maestro había asimilado la teoría de los órdenes clásicos y era ya capaz de proponer su propia lectura de la tratadística arquitectónica. Por otro lado, la portada de San Vicente tuvo cierto eco en la región y, convenientemente simplificada, sirvió como modelo para la entrada (1591-92) de la iglesia parroquial de Nuestra Señora del Remedio (El Remedio, Nava), hasta el momento de autor desconocido (fig. 8), aunque se ha propuesto la intervención de Domingo de Mortera ${ }^{60}$.

En cuanto al monasterio de San Juan Bautista de Corias, su incorporación a la Congregación de Castilla fue algo más tardía, pues tuvo lugar en $1537^{61}$. No obstante, hasta finales del siglo $X V I$ no se documentan reformas importantes en el cenobio. En estas fechas se abordó la reconstrucción general de todo el conjunto de origen medieval bajo unos planteamientos rigurosamente clasicistas y, de nuevo, con la intervención de Juan del Ribero62. En 1590 Domingo de Mortera contrató la construcción de una parte del claustro con arreglo a las trazas elaboradas previamente por Juan del Ribero63. El claustro proyectado por Ribero no ha llegado hasta nosotros, pues fue destruido en el incendio que asoló la mayor parte del conjunto en 1763, y no es posible analizar su diseño ${ }^{64}$. No obstante, el nuevo templo, cuyas obras se habían iniciado en 1593, no se vio afectado por la catástrofe y aún se conserva ${ }^{65}$. En la construcción de esta iglesia trabajó el maestro Domingo de Argos (†1614) hasta 1609, cuando todavía quedaba por edificar la cúpula, pero aún no se ha documentado la autoría del proyecto ${ }^{66}$. Sin embargo, teniendo en cuenta que las obras se iniciaron bajo el mandato de Antonio Yepes (1592-95), que había gobernado anteriormente San Vicente de Oviedo (1589), y que Ribero ya había dado trazas para el claustro, probablemente integrado en un proyecto de reconstrucción del todo el conjunto o traza universal, tal como había hecho en Valladolid, parece razonable pen- 
sar que este maestro pudo ser también el autor del proyecto de la iglesia ${ }^{67}$.

El templo de Corias presenta planta de cruz latina con una sola nave, testero plano, capillas laterales y crucero destacado. Según apuntó Ramallo, la gran cúpula sobre pechinas del crucero sugiere el compromiso entre un espacio centralizado y otro longitudinal, pero todo el conjunto destaca por su sobriedad y armonía de proporciones ${ }^{6}$. Al igual que en San Vicente, Ribero dispuso esbeltas pilastras estriadas, en este caso de orden toscano, entre las capillas para modular los tramos del muro y, sobre ellas, acomodó un entablamento clásico, con friso desnudo, dentículos y cornisa ligeramente volada. De nuevo, el empleo acompasado del orden contribuye a sistematizar e integrar los espacios del templo benedictino, generando un conjunto armónico, que, en este caso, alcanza mayor coherencia al tratarse de un proyecto ex novo.

En cuanto a la portada, reitera un esquema ya conocido de Ribero, que Bustamante García calificó de italiano69, y contribuye al concepto integrador del conjunto (fig. 9). Se dispone entre dos rotundas fajas de sillería que se prolongan en altura hasta sostener el frontón que remata el imafronte. Está formada por un arco de triunfo organizado mediante pilastras pareadas toscanas flanqueando un arco de medio punto y sosteniendo un entablamento clásico con friso de metopas y triglifos. Las pilastras presentan el fuste liso y entre ellas se disponen recuadros de escaso resalte, por lo que la apariencia del conjunto es de sobriedad y escasa plasticidad. Además, la eliminación de las hornacinas vacías que Ribero había dispuesto en San Vicente, San Isidoro y La Santa Espina resta contraste al conjunto. El carácter plano de este cuerpo inferior es aliviado en el superior al disponer una hornacina para el santo titular flanqueada por pilastras toscanas con fuste estriado, que remiten al orden del interior del templo y soportaban un frontón triangular, hoy desaparecido. A ambos lados de las pilastras figuran sendas pirámides rematadas con bolas de inspiración herreriana e, incluso, se advierten también unos aletones muy breves que vinculan ambos cuerpos.

El trabajo de Juan del Ribero Rada en Asturias estuvo vinculado a la reforma de los cenobios

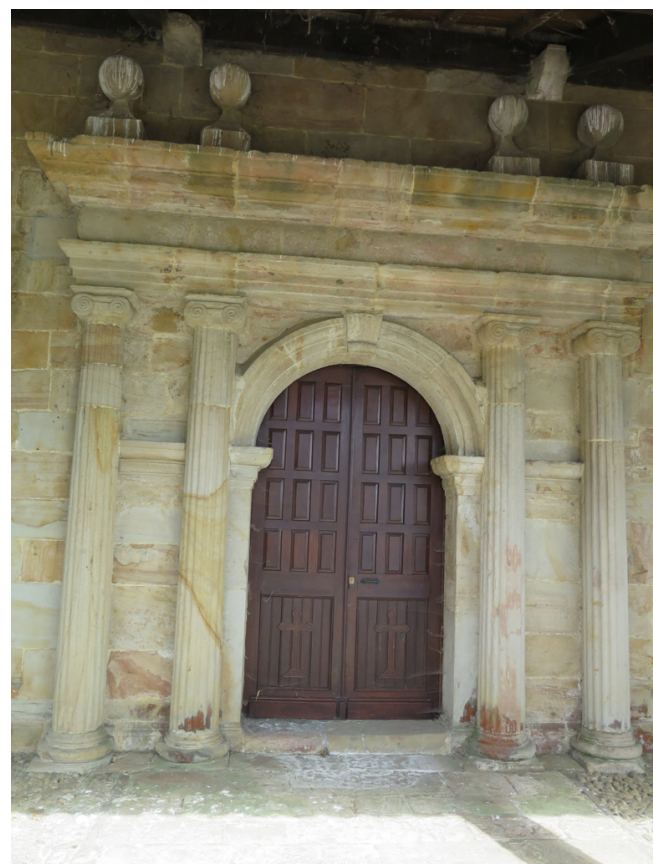

Fig. 8. Iglesia parroquial de Nuestra Señora del Remedio (1591-1592) en El Remedio, Nava. Fachada principal

benedictinos y supuso la introducción del primer clasicismo en la región, en sintonía con lo que estaba sucediendo en la corte o en el foco vallisoletano. En sus obras demuestra un perfecto conocimiento teórico y una notable capacidad creativa, que le permite desarrollar nuevos tipos constructivos en unos proyectos donde los órdenes actúan siempre como garantes de una arquitectura nueva, humanista y de inspiración italiana.

Al mismo tiempo que Ribero, trabajó en la región el arquitecto jesuita Juan de Tolosa (Salamanca, 1548-Oviedo, 1598), que fue el responsable del proyecto del Colegio de San Matías en Oviedo ${ }^{70}$ (fig. 10). La obra de Tolosa muestra también aspectos del primer clasicismo de la escuela vallisoletana y acusa el influjo escurialense. El colegio jesuítico fue una fundación de Magdalena de Ulloa (Toro, Zamora, 1525-Valladolid, 1598), quien ya había ejercido su mecenazgo en la creación de la Colegiata de San Luis en Villagarcía de Campos (1572) y, posteriormente, promovió también la implantación del Colegio de la Anunciación de Santander (1594) ${ }^{71}$. Para 


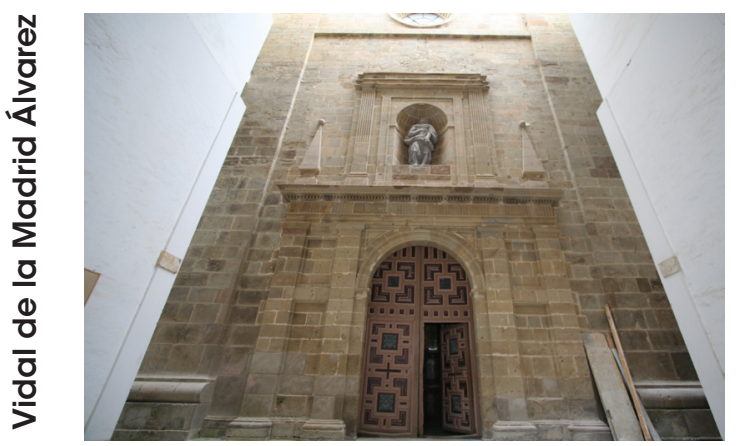

Fig. 9. Iglesia del monasterio de San Juan Bautista de Corias (1593) en Cangas del Narcea. Fachada principal. Fotografía de Alejandro García

materializar la fundación de Ulloa, Juan de Tolosa se trasladó a Oviedo, donde ya se encontraba trabajando en 1584 en las dependencias del colegio jesuítico -hoy desaparecido-, que se concluyó en torno a 1593. Por su parte, el templo no inició su construcción hasta $1616^{72}$, cuando Tolosa ya había fallecido, y no se finiquitó, tras varias alternativas, hasta un siglo más tarde, lo cual plantea el problema de la autoría del maestro salmantino, que hasta el momento no ha sido posible aclarar documentalmente. Además, el largo tiempo transcurrido desde su concepción primitiva provocó que la idea clásica inicial se fuera diluyendo entre aportaciones características del barroco decorativo. En cualquier caso, Tolosa residió en Oviedo durante largos periodos de tiempo ocupándose de los trabajos del colegio e incluso falleció en la ciudad durante una epidemia de peste, por lo que parece razonable suponer que, como propone Ramallo Asensio, este arquitecto habría sido el responsable de trazar un proyecto general del conjunto, que, en el caso de la iglesia, se materializó tras su muerte ${ }^{73}$.

El templo ovetense de San Matías, en la actualidad ocupado por la parroquia de San Isidoro el Real, reproduce el característico modelo jesuítico de planta de cruz latina con una sola nave, crucero sin destacar, capillas laterales comunicadas entre sí y testero recto. Las paredes de la nave se articulan mediante pilastras de orden corintio, pero, a lo largo del dilatado proceso constructivo, la idea inicial clasicista fue sustituida por una interpretación barroca del espacio y de los elementos arquitectónicos elaborada por el maestro avilesino Francisco Menéndez Camina el Viejo (h. 1629-h. 1694)74. En la fachada se ha efectuado también esta reinterpretación decorativa de la idea inicial, pero aún mantiene el cuerpo inferior más o menos intacto y fiel al proyecto primitivo. Se trata de un arco de triunfo de orden toscano compuesto mediante columnas pareadas flanqueando un acceso adintelado y sosteniendo un entablamento con un friso clásico de rosetas y triglifos inspirado en modelos serlianos. Entre las columnas se disponen recuadros muy planos y el conjunto se destaca elevándolo sobre un zócalo y proyectándolo sobre la línea del muro de la fachada. Las puertas que flanquean la portada también responden a esta primera fase edificatoria, pero el resto de la fachada evidencia el capricho y la inflación decorativa característicos del último cuarto del siglo XVII. La portada ha sido relacionada con la iglesia de las Angustias de Valladolid, trazada por Juan de Nates, que presenta un esquema compositivo muy similar tan sólo variando el orden columnario, que pasa a ser corintio, y transformando dos recuadros en nichos para esculturas. También está relacionada con la fachada del Colegio del cardenal en Monforte de Lemos, donde intervino el propio Tolosa, que también emplea el orden toscano, pero la portada es más plana, menos plástica y pierde monumentalidad75.

\section{El segundo clasicismo}

Los proyectos arquitectónicos de Ribero y Tolosa facilitaron la implantación en la región del gusto clásico a finales del siglo XVI. Con ellos llegó la cultura artística de la escuela vallisoletana caracterizada por la influencia de Herrera, especialmente a través de la Cuarta Colegiata -después catedral-, el conocimiento de la Antigüedad romana, que se adopta como modelo creativo, y un sustrato humanista que se manifiesta en la amplia formación teórica de sus principales artífices, que llegaron, incluso, a traducir a alguno de los tratadistas más relevantes, como Vitrubio o Palladio. Este primer clasicismo arraigó sin dificultad en Asturias e incorporó la región a la vanguardia artística castellana, poniendo las bases de una práctica artística que se mantuvo con pujanza a lo largo de la mayor parte del siglo XVII alentada por la actividad de los maestros montañeses. 
La consolidación de esta propuesta clásica en la región fue protagonizada por el arquitecto Juan de Naveda, quien ya se encontraba en Oviedo en 1621 para edificar la girola de la catedral ${ }^{76}$ (fig. 11). Naveda se había formado en el taller de los Sisniega y trabajó brevemente en las obras del conjunto clasicista de Lerma, donde conoció los proyectos del arquitecto cortesano Francisco de Mora (Cuenca, 1552-Madrid, 1610) y del carmelitano fray Alberto de la Madre de Dios (Santander, 1575-Pastrana, Guadalajara, 1635)77. Era, por tanto, un buen conocedor del primer clasicismo practicado por los arquitectos de la generación de Herrera, quienes, en su mayor parte, ya habían desaparecido al iniciarse el siglo XVII, y había madurado profesionalmente junto a sus sucesores, que representaban la continuidad clásica en un momento de expansión, pero también de diversificación del estilo. En realidad, su trayectoria discurrió paralela al desarrollo de la última fase de la escuela vallisoletana, encarnada en la obra del arquitecto Francisco de Praves (Valladolid, 1586-Madrid, 1637), traductor de tratadistas italianos y depositario final de un tradición artística que comenzó a declinar con su desaparición ${ }^{78}$. Al igual que Praves, Naveda había asimilado la tradición escurialense en unas composiciones severas, planas y funcionales, pero también supo evolucionar hacia una mayor expresividad, donde el rigor de los órdenes y el sistema de proporciones se mantuvieron como una constante creativa.

La llegada de Juan de Naveda a Oviedo inició el proceso de adaptación del conjunto catedralicio a los nuevos usos contrarreformistas ${ }^{79}$. Su proyecto para la girola (1621-1633) no se limitó a trazar el consabido deambulatorio que facilitaba la circulación en torno al presbiterio, sino que desarrolló una estructura más compleja donde se integran con naturalidad, una nueva capilla para santa Eulalia (hoy Covadonga), cinco capillas más para los apóstoles, que figuraban en la advocación primitiva del templo y aún no contaban con ubicación adecuada, y una gran sacristía para acomodar los nuevos ornamentos litúrgicos ${ }^{80}$. El trascoro ideado por Naveda emplea un léxico clasicista de singular austeridad, pese al revestimiento barroco que experimentó en el siglo XVIII, pero respeta la estructura del templo gótico y busca integrarse con él por medio de recursos de maquillaje compositivo, como la crucería pétrea,

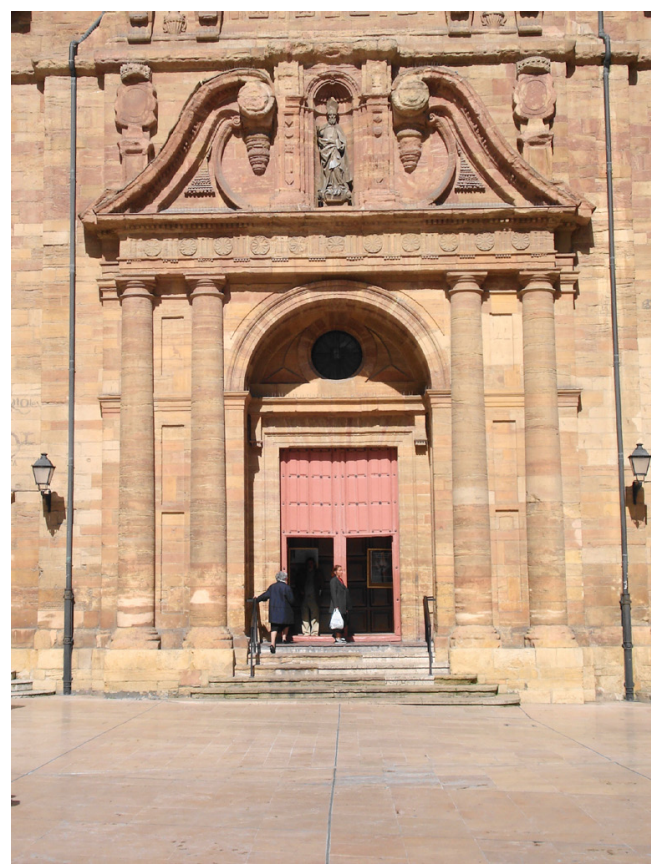

Fig. 10. Iglesia del colegio de San Matías de Oviedo (16161725), hoy iglesia parroquial de San Isidoro el Real. Fachada principal

que facilitan una aparente transición sin traumas desde el edificio medieval ${ }^{81}$.

La girola fue concebida como un pasillo que comunica los dos brazos del transepto y al que se van abriendo las capillas dispuestas entre machones. Hacia el deambulatorio, estos pilares se revisten de pilastras toscanas pareadas, que flanquean un nicho y reciben los arcos fajones de la bóveda. Al otro lado, los arcos descansan sobre unas pilastras toscanas cajeadas más anchas, que cubren los contrafuertes de la capilla mayor. El acceso a cada una de las capillas también se destaca mediante pilastras que soportan sus correspondientes arcos. Las capillas se cubren con bóveda de cañón y en el abovedamiento del pasillo se introducen las nervaduras goticistas sin función estructural para procurar la conciliación con el resto del templo. Por su parte, la primera capilla del acceso meridional, hoy dedicada a Nuestra Señora de Covadonga, se trazó como una planta centralizada, prácticamente una cruz griega, que organiza sus muros con las mismas pilastras toscanas del deambulatorio flanqueando recuadros 


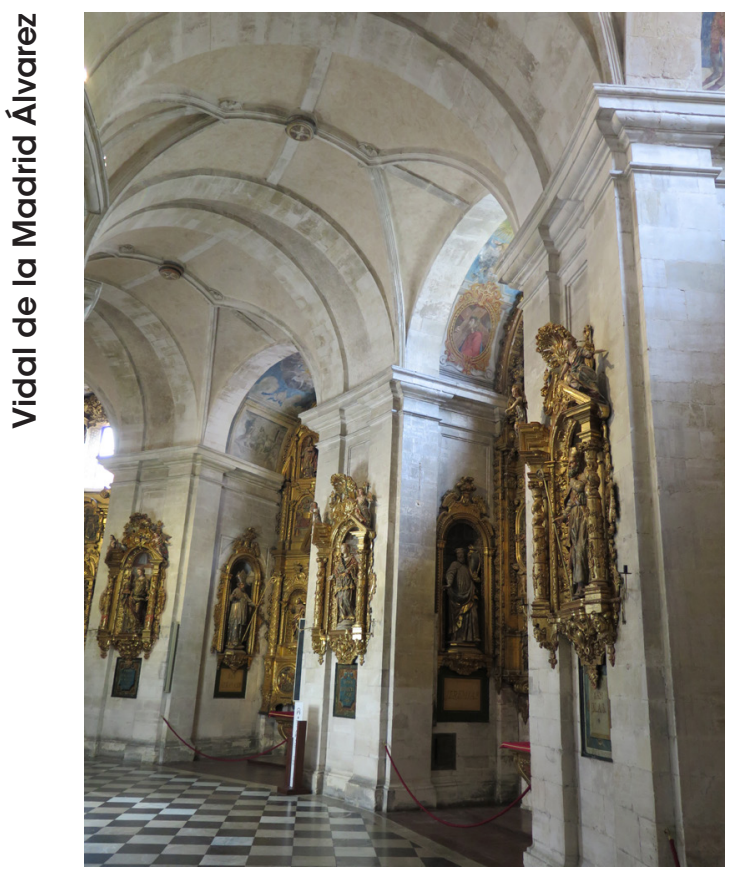

Fig. 11. Girola de la catedral de Oviedo (1621-1633)

muy planos y también introduce la crucería en la cubierta. En correspondencia con este hueco, al otro lado del deambulatorio, Naveda dispuso el acceso a la antesacristía, concebida como un espacio longitudinal abovedado que da paso a la sacristía, donde aparecen de nuevo las pilastras toscanas de la girola (fig. 12). En la actualidad, se encuentra muy transformada por las reformas del primer tercio del siglo XVIII, pero en su origen probablemente se trazó como una planta de cruz latina con los brazos y la cabecera más cortos y sin la cúpula actual ${ }^{82}$.

El conjunto de la girola no sólo revela la habilidad como tracista de Naveda, pues compone un artefacto arquitectónico monumental, bien trabado con la obra gótica y perfectamente ajustado a la multiplicidad de funciones del programa, sino también su capacidad para manejar con soltura el lenguaje clásico. Toda la obra descansa sobre la flexibilidad compositiva de las pilastras toscanas, que se van combinando en los distintos espacios manteniendo el sistema de proporciones y suministrando unidad al conjunto. Las pilastras pareadas asociadas con arcos fajones aparecen ya en la basílica del monasterio de El Escorial y el cajeado longitudinal de pilastras fue empleado por Herrera en los pilares de la cuarta colegiata, de donde pasó a la escuela vallisoletana. La inspiración herreriana del proyecto parece clara, pero, además, se ha identificado el empleo de una lámina de Serlio para una puerta de la Capilla de Covadonga ${ }^{83}$ y la portada de la antesacristía revela una innegable filiación vignolesca ${ }^{84}$. Esta portada, compuesta de sendas columnas corintias que sostienen un entablamento sobre el cual se dispone un ático entre pilastras, emplea el modelo de capitel reproducido por Vignola en su Regla y su diseño parece inspirado en la lámina 39 de dicho tratado. Semejante esquema compositivo, aunque manteniendo el orden toscano, ya había sido empleado por fray Alberto de la Madre de Dios en la colegiata de San Pedro de Lerma (1617), donde, al igual que en la catedral de Oviedo, se ilustran las enjutas del arco con la escena de la Anunciación. Finalmente, por ahora, resulta más complejo determinar el origen del diseño de la puerta de la sacristía, que fue reinterpretado por Menéndez Camina algunas décadas más tarde para la fachada de la iglesia jesuítica de Oviedo. Esta entrada aparece realzada con un vistoso frontón curvo de base quebrada, apoyado en grandes ménsulas y decorado interior y exteriormente con denticulado, que ha sido relacionado con el repertorio de portadas publicadas por Domenico Fontana (Melide, Suiza, 1543-Nápoles, 1607) en $1590^{85}$.

La presencia de Naveda en la catedral de Oviedo facilitó, sin duda, su contratación para erigir la capilla de la Anunciación (h. 1626-1640) en el flanco septentrional del templo86 (fig. 13). Esta obra fue promovida por el prelado asturiano Juan Vigil de Quiñones (†1627), que ocupó las sedes de Valladolid y Segovia, para destinarla a su enterramiento. Naveda, que ganó espacio a costa de la antigua basílica altomedieval del Rey Casto, concibió la capilla como un templo centralizado dispuesto en torno a una gran cúpula vaída sobre pechinas con un óculo que evidencia su inspiración en el Panteón romano ${ }^{87}$. Los muros se estructuran mediante recuadros y enérgicas pilastras estriadas de orden corintio con factura esmerada y vocación monumental. En esta obra, el arquitecto, aunque mantiene la cadencia y ordenación de elementos de la girola, se liberó de la planitud y contención herrerianas para ganar volumen, ex- 
presividad y contraste. Su planteamiento ya había sido esbozado en la portada de la antesacristía y ahora insiste en el léxico viñolesco, que le proporciona el modelo del orden corintio. Además, en el retablo tallado por el escultor Luis Fernández de la Vega (Llantones, Gijón, 1601-Oviedo, 1675), que Ramallo Asensio supone con acierto que ha sido trazado por el propio Naveda a causa de su evidente sintonía con el resto de la obra ${ }^{88}$, se reiteran de nuevo los modelos viñolescos ${ }^{89}$. Así, tanto el orden corintio de las columnas pareadas del nivel inferior, como el orden compuesto de las dos columnas que flanquean el relieve del Bautismo de Cristo parecen tomados del tratado de Vignola y redondean una feliz unidad de estilo.

La capilla de la Anunciación o del obispo Vigil inició la serie de grandes capillas de la catedral ovetense promovidas por sus prelados, que, además de su función funeraria, cumplen otros cometidos de especial interés para el cabildo, como un nuevo relicario (Nueva Cámara Santa), una capilla para la patrona de la diócesis (Santa Eulalia) o una nueva capilla real con un santuario para la Virgen de las Batallas (Rey Casto). La Nueva Cámara Santa (1660-62), hoy capilla de Santa Bárbara, realizada por Ignacio de Cajigal (†1666) supuso la introducción del gusto barroco en el conjunto catedralicio, evidenciado por su temática ornamental, su función de relicario y su sentido escenográfico, pero se dejó influir por el orden corintio plasmado por Naveda en la Anunciación y conservó el aire clásico en su estructura. La portada, por su parte, recupera la sobriedad de la girola con dos pilastras toscanas lisas soportando un frontón rematado con esferas ${ }^{90}$.

Naveda trazó también el ayuntamiento ovetense (1621-1633) utilizando un módulo arcobalcón de resonancias palladianas y un cuerpo para el arco de Cimadevilla con serliana en el balcón principal que reproduce el modelo herreriano del ayuntamiento toledano en la plaza de Zocodover (1596)91. En general, toda la obra rezuma clasicismo con la mirada puesta en la escuela vallisoletana, pues la retícula de las fajas remite a la fachada de la biblioteca de El Escorial hacia el Patio de los Reyes o al diseño de Francisco de Praves para el claustro de las Huelgas Reales de Valladolid (1622), y el cuerpo del Arco de Cimadevilla recuerda al Humilladero de la

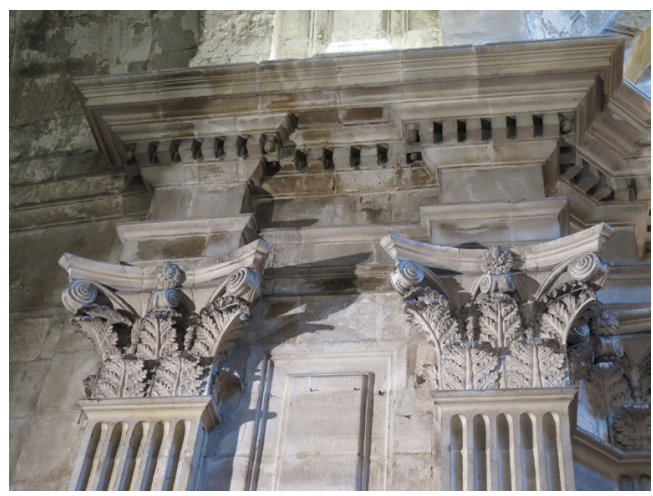

Fig. 12. Capilla de la Anunciación (h. 1626-1640) en la catedral de Oviedo. Detalle de las pilastras

Quinta Angustia (1591) de Juan de Nates. Por último, Naveda construyó al menos dos capillas privadas en Asturias: la de la Concepción en la Torre de la Pedrera en Villaviciosa (1623) y la de los Reyes Magos en el palacio de Villabona en Llanera (1623) ${ }^{92}$. En ellas, se mantiene el rigor, la austeridad y la contención clásicos característicos de la girola catedralicia, con las pilastras toscanas y arcos fajones actuando de nuevo como organizadores de la composición, y se confirma una auténtica fórmula edificatoria.

El clasicismo estricto y monumental representado por Naveda fue evolucionando a mediados de siglo hacia propuestas menos rigurosas que avanzaban hacia el barroquismo. La obra de Melchor de Velasco Agüero (†1669) en Asturias representa muy bien estas tendencias, pues combina el clasicismo declinante con algunas soluciones heterodoxas que alcanzaron su desarrollo en sus obras gallegas ${ }^{93}$. Los cuatro años que permaneció en la región antes de trasladarse a Galicia (1654-58) desplegó una gran actividad dirigida, de forma especial, hacia la reforma de los grandes complejos monásticos. En Oviedo, Velasco trazó la reforma del monasterio de San Vicente (1658), proporcionándole una sobria fachada urbana donde destaca la nueva portada tomada del Arte y Uso de Arquitectura (1639 y 1665) de fray Lorenzo de San Nicolás (Madrid, 1593-1679), y diseñó la modernización del monasterio de San Pelayo (h. 1657), cuyo claustro, ejecutado por Cajigal en 1664, evidencia aún planteamientos clasicistas y remite a los patios renacientes de la Universidad, el monasterio de San Francisco de 


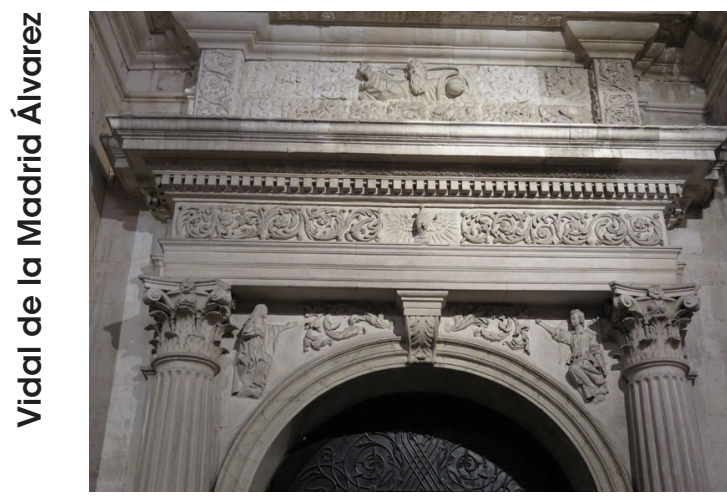

Fig. 13. Sacristía de la catedral de Oviedo (1621-1633). Portada de la antesacristía

Avilés y el monasterio de Santa María de Belmonte al recuperar el doble ritmo de columnas toscanas en el primer piso, que se transforman en pilares en la planta superior (fig. 14). Su última obra en Asturias, el claustro del monasterio de Santa María la Real de Obona en Tineo (1658), revela la capacidad del autor para monumentalizar una obra modesta con recursos limitados y estrictamente clásicos. Con este fin, dispone sobre pedestales una serie de austeras pilastras toscanas de orden gigante con su correspondiente segmento de entablamento, que marcan el ritmo de una galería cuyos entrepaños se recorren por unas fajas muy planas para realzar las ventanas y sugerir la unidad reticulada del muro.

\section{La persistencia del clasicismo y la misce- lánea barroca}

Los proyectos de Juan de Naveda consolidaron el gusto clásico, que mostró su fortaleza a lo largo de gran parte de la centuria de la mano de los maestros montañeses, que protagonizaron la actividad constructiva en la región durante ese periodo. En realidad, la persistencia del clasicismo en Asturias más allá de mediados del siglo XVII no puede justificarse tan sólo por una causa, sino que responde a motivaciones de naturaleza diversa.

En primer lugar, Naveda había logrado plasmar su propia interpretación del léxico clásico, derivada de Herrera y de la escuela vallisoletana, en unas fórmulas arquitectónicas de singular eficacia, que siguieron utilizándose en la segunda

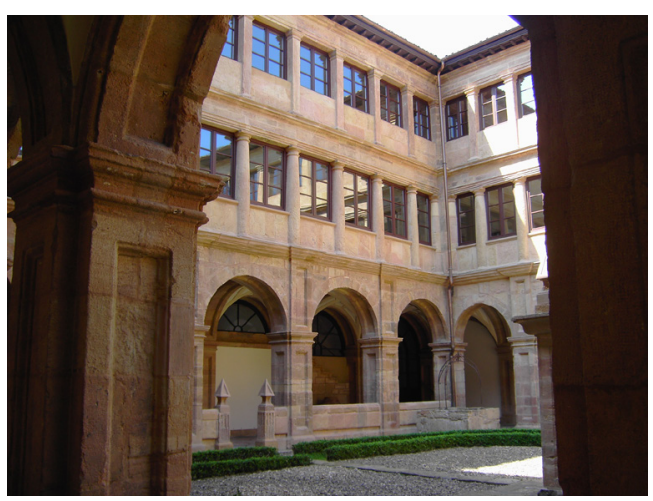

Fig. 14. Monasterio de San Pelayo en Oviedo. Claustro (1664). Fotografía de Yayoi Kawamura

mitad del siglo. Tal vez el mejor ejemplo sea la propuesta del Ilanisco Juan de Estrada (h. 1621post. 1684) para las casas consistoriales de Avilés (1670-77), donde reproduce fielmente la idea de Naveda para el ayuntamiento ovetense ${ }^{94}$. Al igual que en la capital asturiana, el edificio consistorial avilesino se concibió como portada ciudadana, erigiéndose delante de la muralla medieval, y se diseñó también con dos alas porticadas unidas por un cuerpo central (fig. 15). Se trabajó de nuevo con el módulo arco-balcón, se reiteraron las fajas que estructuran el muro, aunque con un concepto aún más simplificado, y se replicó una calle central idéntica, que mantiene la cita serliana. Además, Estrada también se fijó en el modelo de capilla privada de Naveda para trazar la capilla y oratorio cubierto con media naranja (1668) que le encargó Sebastián Vigil de la Rúa (1628-1692) para su casa en Oviedo y que nunca llegó a ser realizada ${ }^{95}$.

En una línea similar trabajó el arquitecto trasmerano Gregorio de la Roza (h. 1644-h. 1706), quien a la muerte de Cajigal se ocupó de su taller tras casarse con su viuda. Roza, que trabajó de forma continuada en Asturias hasta principios del siglo XVIII, llegó a ser maestro de obras del Principado (1672) y, en un momento de apogeo del barroco decorativo, sus obras evidencian contención ornamental y una clara continuidad con los planteamientos clasicistas, que le llevó incluso a recrear el modelo de las consistoriales ovetenses en la sala capitular de la Colegiata de Santillana del Mar en Cantabria (1694) ${ }^{96}$. La huella de Naveda se dejó sentir también en su diseño para la capilla de San 
Pedro de Rozadas en Villaviciosa (1675-77)97, que fue promovida por el canónigo de la catedral de Toledo Juan Santos de San Pedro, pero en las casas de Malleza llegó aún más lejos en la búsqueda de referentes clásicos. Fernando de Malleza y Dóriga encargó a Roza la erección de sus casas familiares (1673-1675) $)^{98}$ en Oviedo, probablemente el primer palacio moderno de la capital. Están emplazadas en la antigua plaza de la Fortaleza -hoy, Porlier-, que era la zona de privilegio por excelencia para la nobleza avecindada en Oviedo, y a escasos metros de la Universidad, que decidió tomar como modelo. La calle central de estas casas reproduce el esquema de la portada universitaria: una puerta adintelada flanqueada por sendas columnas dóricas de fuste estriado sobre pedestales, que sostienen un entablamento con friso de triglifos y rosetas y un balcón sobre éste flanqueado por los escudos nobiliarios (fig. 16). En esencia, se trata del mismo diseño, pero, además, los capiteles reproducen también modelo vignolesco de ovas, aparecen las mismas traspilastras y se reitera el entablamento del edificio universitario, probablemente tomado de Serlio, aunque en el palacio de Malleza se permite la licencia de quebrarlo sobre las columnas. Por último, los aspectos novedosos de esta idea también nos llevan a Serlio, pues el balcón del primer piso aparece flanqueado por pilastras jónicas que sostienen un friso convexo bajo una cornisa con dentículos, que evidencian claramente su inspiración en el Libro Quarto de Architectura del tratadista boloñés.

Otro factor que influyó en la persistencia del clasicismo en Asturias fue la desaparición de los maestros que habían protagonizado la actividad arquitectónica a mediados del siglo. Velasco se había ido a Galicia en 1658, Cajigal falleció ocho años después y tan sólo Roza estaba cualificado para ocupar su espacio. La ausencia de estos arquitectos dificultó la evolución del estilo hacia las formas barrocas que ya se advertían en sus obras y Gregorio de la Roza, ya fuera por la inercia de la clientela o por sus propias limitaciones, se conformó con dar continuidad a los planteamientos artísticos de los maestros que lo precedieron, sin abordar auténticas novedades creativas.

Este retraimiento de los trasmeranos facilitó la hegemonía de los asturianos Menéndez Camina, quienes introdujeron el barroco decorativo en la

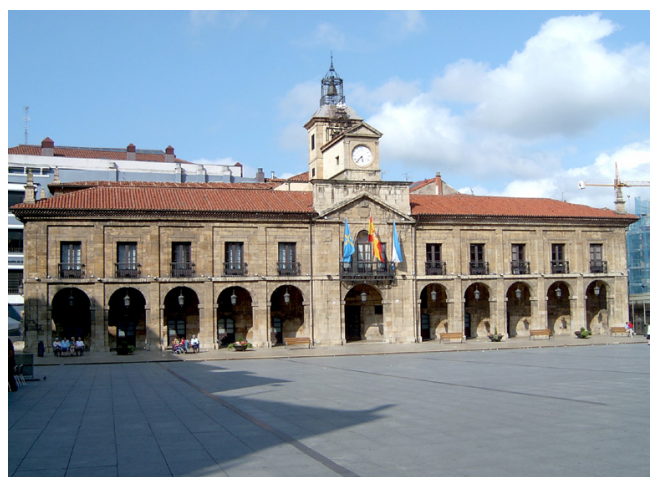

Fig. 15. Casas consistoriales de Avilés (1670-1677)

región. El planteamiento artístico de Francisco Menéndez Camina el Viejo, que tuvo continuidad en la obra de su hijo, Francisco Menéndez Camina el Mozo (h. 1662-†1719), es deudor de la propuesta gallega contemporánea, pero no se desvincula totalmente de la tradición, pues superpone unos recursos ornamentales caprichosos, imaginativos $y$, con frecuencia, exuberantes, sobre unos esquemas constructivos más conservadores ${ }^{99}$. Así sucede con su proyecto para la capilla de Santa Eulalia en la catedral de Oviedo (169096) ${ }^{100}$, donde se tiene muy presente la propuesta de Naveda para la capilla de la Anunciación, o sus trazas para las casas del marqués de Camposagrado en Avilés, donde, como ya se ha comentado, se toma como modelo la fachada del palacio de Valdés ideada por Portigiani. Para la capilla de Santa Eulalia, tras valorar con el promotor, el prelado fray Simón García Pedrejón (Torquemada, Palencia, 1618-Oviedo, 1696), al menos tres proyectos diferentes, idearon una planta centralizada cubierta con media naranja sobre pechinas y, al igual que Naveda en la Anunciación, sugirieron la posibilidad de dejar un óculo abierto sin linterna para iluminar el interior. Además, recurrieron también a la cornisa y a las pilastras corintias de la Anunciación, que suministran la misma sensación de orden gigante al distribuir el muro en dos niveles, pero se eliminaron las estrías del fuste para cajearlo y ocuparlo con una decoración de colgantes de hojas y frutos que truecan en el nivel inferior en recuadros vegetales. Semejante ornamento recuerda las ristras de frutos de las portadas de Serlio, pero muestra también un indudable parentesco con la temática del barroco 


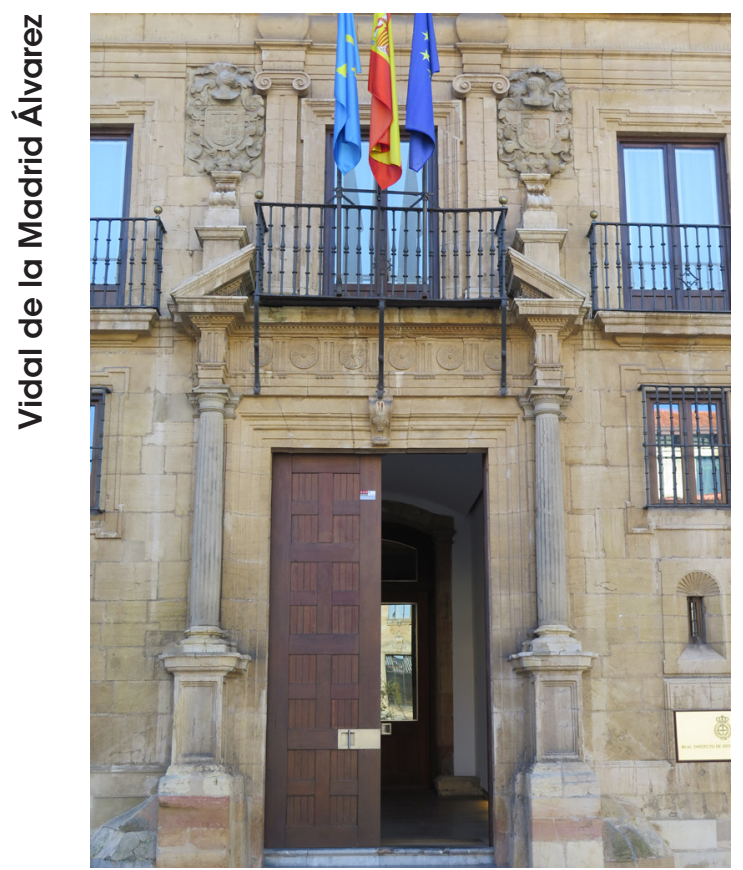

Fig. 16. Casas de Fernando de Malleza (1673-1675) en Oviedo, hoy sede del RIDEA

gallego contemporáneo (Monteagudo, Andrade o Romay). En cuanto al palacio del marqués de Camposagrado ${ }^{101}$, su vinculación con las torres de Valdés se aprecia en el esquema de cuerpo apaisado entre torres y en la generosa utilización de almohadillado en las esquinas y en la guarnición de los vanos, pero aporta como novedad una calle central organizada mediante la superposición de órdenes. No se trata, desde luego, de los órdenes clásicos, sino de una interpretación personal de los mismos elaborada por Menéndez Camina el Viejo, que su hijo recuperó para la fachada del monasterio de San Salvador de Cornellana en Salas (1694)102, aunque en una versión atrofiada. En la planta baja se disponen sendas columnas dóricas con fuste estriado y equino liso; en el piso principal aparecen columnas con capitel corintio estilizado y fuste de estrías torsas; en la planta superior se utilizan similares capiteles corintios, pero las columnas presentan fuste salomónico de cinco espiras decorado con pámpanos y racimos de vid. Todas las columnas está asociadas a sus correspondientes traspilastras de fuste cajeado y soportan fragmentos de entablamento con el fuste decorado con motivos vegetales, pero resultan de difícil adscripción a un prototipo concreto.

Menéndez Camina el Mozo prosiguió también la adaptación o actualización barroca de los órdenes clásicos iniciada por su padre. En este aspecto, resulta ejemplar su propuesta para las casas del indiano Rodrigo García Pumarino (†1706) en Avilés (1700-1706)103, donde reinterpreta la fachada de las consistoriales de la ciudad -trazadas, según hemos visto, por Estrada imitando a Naveda- introduciendo el orden jónico. Se repite el módulo arco-balcón entre fajas con pórticos, pero las fajas lisas del consistorio se transforman en pilastras jónicas de orden gigante con fuste rehundido y un tratamiento muy estilizado. Se asume, por tanto, el modelo clasicista de Naveda-Estrada, cuya estructura y proporciones favorecen la integración en el entorno urbano, pero se le somete a un proceso de modernización que supone la introducción de una lectura personal de los órdenes clásicos y el empleo de ornamento en la mayor parte de los elementos (imposta, guarnición de las ventanas, rosca de los arcos, cornisa, friso). Semejante utilización de los órdenes se dio también en su proyecto para el conjunto de las casas del marqués de San Esteban del Mar de Natahoyo (1705-1716) y colegiata de San Juan Bautista en Gijón (17051734) ${ }^{104}$. La fachada principal del cuerpo central de las casas muestra una estructura reticular inspirada en la vicaría del monasterio de San Pelayo de Oviedo (1703-1704)105, que había trazado fray Pedro Martínez de Cardeña (fig. 17), pero el artefacto columnario diseñado por el fraile arquitecto se convirtió en un recurso mucho más estilizado, que sólo mantiene las columnas en la calle central y las sustituye en el resto de la obra por pilastras cajeadas. Además, Menéndez Camina volvió a interpretar los órdenes clásicos de forma caprichosa y utilizó soportes jónicos con fuste estriado en la planta baja, corintios con fuste de estrías torsas en el primer piso y probablemente corintios, pues se hace difícil la interpretación pues la erosión ha desfigurado los capiteles, en la planta superior. El rigor clasicista de Martínez de Cardeña quedó diluido, por tanto, en una visión más imaginativa y arbitraria. En cuanto a la colegiata, diseñó un gran templo de tres naves separadas por arcadas sobre pilares con pilastras de capitel jónico en correspondencia con los arcos fajones de la nave central. Estas pilastras presentan una solución an- 
ticlásica y sugerente, pues su fuste se talla como si contuviese el fuste cilíndrico de una columna en su interior. Al exterior se retoma el almohadillado característico de las cercanas casas de Valdés y su portada meridional, similar a la utilizada en la capilla de Santa Eulalia en la catedral ovetense, se compone con dos columnas jónicas de fuste estriado tratadas con la habitual estilización de este maestro, pero que soportan sendos tramos de friso convexo, tal vez inspirados en láminas de Serlio.

La última causa que podría justificar la persistencia del clasicismo en la región probablemente tenga que ver con el menor coste de unas obras sobrias, carentes de ornato y funcionales, que se convirtieron en la solución más adecuada para un territorio con recursos limitados. De esta forma, es posible que pueda explicarse la adaptación para la iglesia y convento de las agustinas recoletas de Gijón (1669-1684; reformado en 1733) del proyecto que Ignacio de Cajigal había trazado para el convento de Nuestra Señora de la Encarnación de Llanes (1665), caracterizado por su contención y funcionalidad ${ }^{106}$.

Finalmente, durante las primeras décadas del siglo XVIII se erigieron dos obras singulares que remueven los modelos tradicionales y se distancian de la arquitectura local. En primer lugar, la vicaría del monasterio de San Pelayo (1703), ya mencionada, que fray Pedro Martínez trazó en Oviedo con sentido monumental y contención vitrubiana, aunque introduce las molduras mixtilíneas en la guarnición de los vanos, que adquirirán cierta fortuna en el panorama asturiano. Nos interesa especialmente su esmerado tratamiento de los órdenes, que combina con el sentido ornamental y compositivo del barroco. El arquitecto diseñó un cuerpo central de tres calles articuladas mediante rigurosa superposición de órdenes: toscano sobre elevado plinto y entablamento con friso de triglifos y metopas en la planta inferior, jónico sobre un pedestal de menor altura en el primer piso y corintio sin plinto en la planta superior. Como ya advirtió el profesor Ramallo, se juega con la disminución progresiva de estos soportes acorde con el diferente destino de cada nivel: arcadas, balcones y ventanas ${ }^{107}$. Además, cada columna se encuentra asociada a una serie de traspilastras de su orden que aumentan en número según ascendemos. En consecuencia,

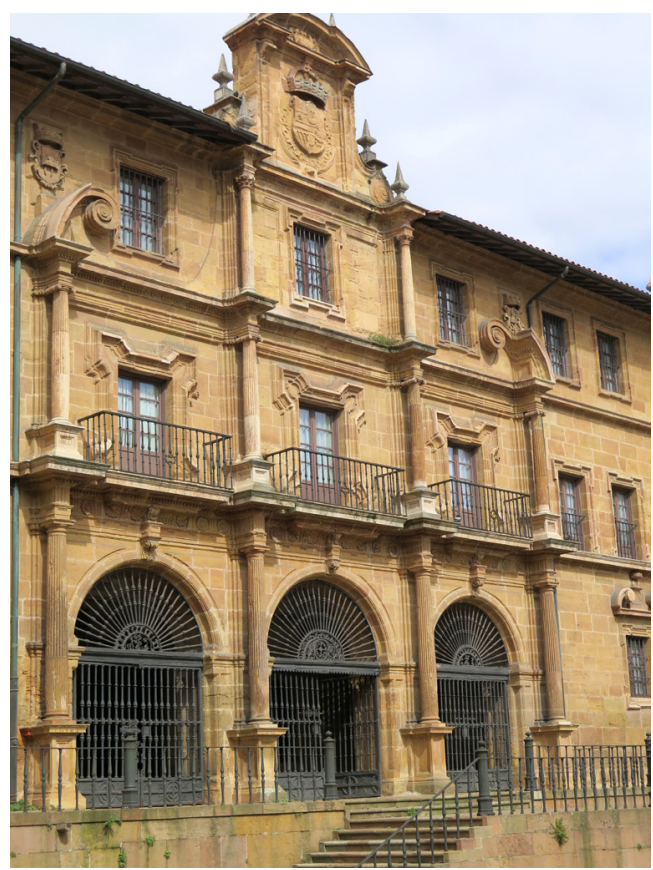

Fig. 17. Vicaría del monasterio de San Pelayo (1703-1704) en Oviedo

juegos visuales e integración de recursos clásicos con un renovado ornamento barroco, que se limita a las guarniciones de los vanos.

Por su parte, el maestro trasmerano Bernabé de Hazas (†1710) reconstruyó la capilla real o basílica del Rey Casto de la catedral de Oviedo (17051712), demoliendo la ancestral iglesia-panteón altomedieval (siglo IX) y recolocando los despojos reales de los miembros de la monarquía asturiana en un mausoleo con urnas, a los pies de la nueva construcción ${ }^{108}$ (fig. 18). Este templo, erigido en plena Guerra de Sucesión como apoyo a la legitimidad del monarca borbón Felipe V (Versalles, 1683-Madrid, 1746), distingue sus espacios mediante el tratamiento diferenciado de las bóvedas -elipsoidal para el santuario mariano de la cabecera, cúpula sobre tambor octogonal para el crucero y crucería goticista para las naves-, pero destaca por su original diseño de los soportes. Se trata de pilares con semicolumnas y pilastras de orden corintio adosadas, que soportan tramos de entablamento sobre los cuales descansan los arcos que separan las naves. El entablamento, compuesto de arquitrabe, friso decorado con motivos vegetales y angélicos 


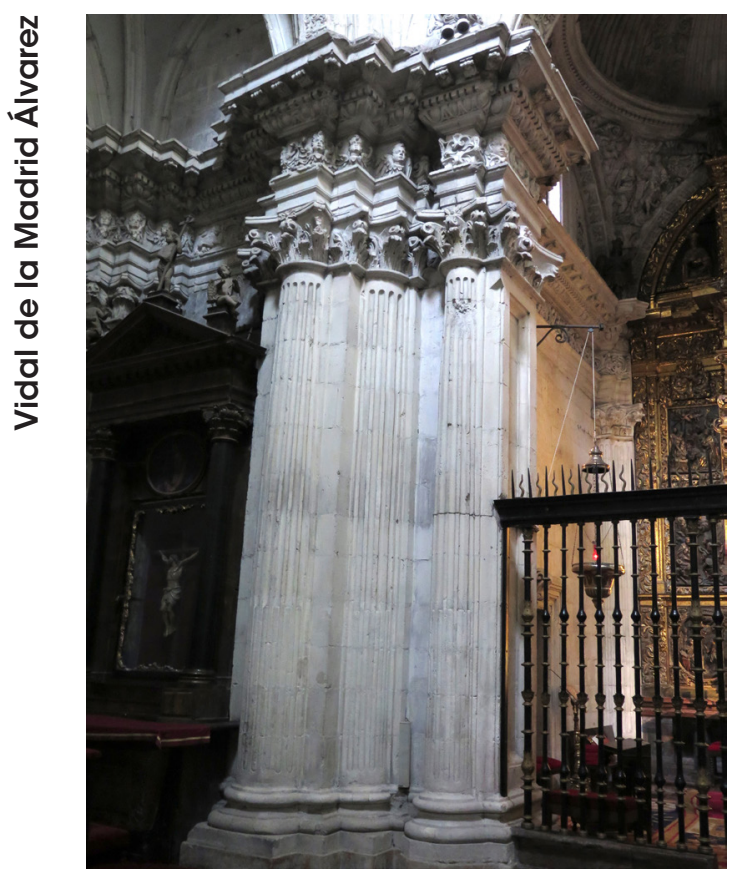

Fig. 18. Capilla Real o Basílica del Rey Casto (1705-1712) de la catedral de Oviedo. Detalle de los pilares

y cornisa con dentículos y ovas, se va quebrando adaptándose a los capiteles de columnas y pilastras y se extiende por el muro interior proporcionando unidad al conjunto. Semejante concepción de los soportes recuerda el diseño de los pilares de inspiración antigua que Diego de Siloé (Burgos h. 1490-Granada, 1563) empleó la catedral de Granada y que en su momento se convirtieron en un auténtico sello de estilo ${ }^{109}$. En Oviedo, por lógicas razones de escala, Hazas prescindió de los pedestales semicilíndricos, pero sus pilares mantienen un indudable parentesco con la catedral granadina, que tal vez tenga que ver con el carácter de capilla y panteón real del templo asturiano.

\section{Epílogo. La restauración del clasicismo}

A mediados del siglo XVIII, los arquitectos comprometidos con la reforma artística propusieron la recuperación de las formas clásicas como lenguaje del nuevo gusto ilustrado. En Asturias, el maestro Pedro Antonio Menéndez (Candás, Asturias, 1716-Oviedo, 1789), responsable del primer aliento reformista en la arquitectura regional, emprendió la restauración del clasicismo recuperando

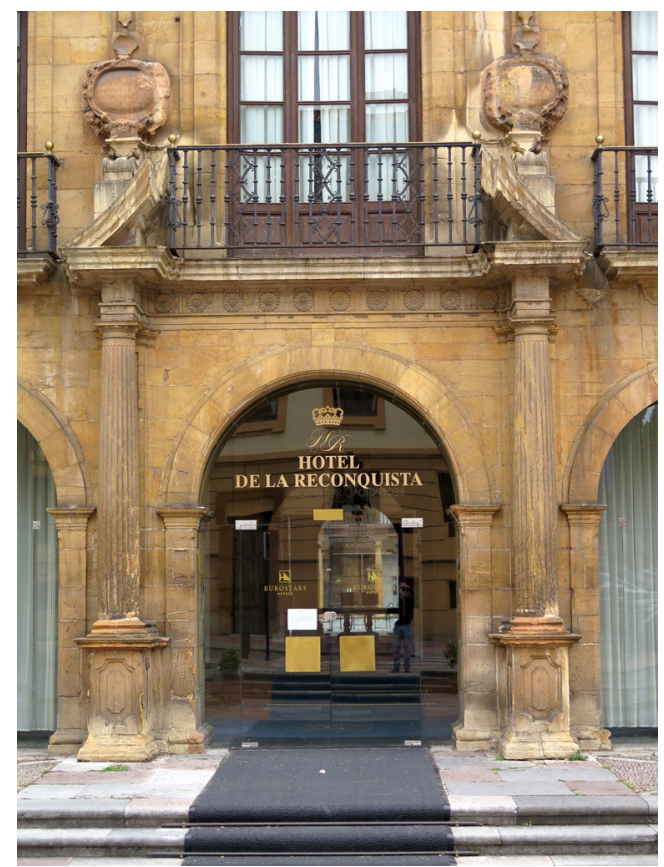

Fig. 19. Hospicio y hospital real de huérfanos, expósitos y desamparados (1752-1770) en Oviedo, hoy Hotel de la Reconquista. Calle central de la fachada principal

modelos y esquemas constructivos, que, como se ha visto, nunca habían llegado a desaparecer del todo'110. Su proyecto para el Hospicio y hospital real de huérfanos, expósitos y desamparados (17521770), hoy Hotel de la Reconquista en Oviedo, constituye el mejor ejemplo de esta propuesta creativa de carácter continuista. El hospicio había sido una iniciativa de Isidoro Gil de Jaz (Sangüesa, 1703-Madrid, 1765), regente de la audiencia de Oviedo (1749-1754) y destacado reformador ilustrado, que había concebido este centro como una institución novedosa para procurar la recuperación e integración social de los niños huérfanos y expósitos, pues tenían la oportunidad de aprender un oficio en sus instalaciones. La posibilidad de erigir un edificio para este fin, donde poner en práctica las ordenanzas elaboradas para su funcionamiento por el propio regente, quien se comprometió también con la idea general del conjunto, convirtieron esta iniciativa en un modelo digno de emulación. En su planteamiento general, Menéndez y Gil de Jaz recuperaron la planta tradicional de los hospitales renacentistas españoles, con una serie de patios, donde se utiliza como soporte la 
columna toscana habitual en los interiores de los palacios asturianos de la Edad Moderna, y una capilla, trazada finalmente por Ventura Rodríguez (Ciempozuelos, Madrid, 1717- Madrid, 1785) en 1768, dispuesta en el eje axial del conjunto. Además, en la fachada principal del hospicio, edificada entre 1752 y 1758 , se aprecia con nitidez el eco de las construcciones del clasicismo local (fig. 19). En ella, Menéndez recuperó el esquema compositivo de Naveda para las consistoriales ovetenses, configurado mediante la reiteración del eje arcobalcón entre fajas y con pórticos en la planta baja, y reprodujo en la calle central la composición vignolesca de las casas de Malleza que Gregorio de la Roza había tomado, a su vez, de la entrada de la Universidad de Oviedo. Así, al igual que Roza, Menéndez dispuso en la calle central columnas dóricas de fuste estriado sobre pedestales, que sostienen un entablamento quebrado con friso de triglifos y rosetas y tramos de frontón a ambos lados de un balcón flanqueado por sendos espejos con inscripción, que sustituyen a los escudos de las casas de Malleza. De esta forma, la restauración reformista comenzó asentándose sobre modelos clásicos muy próximos que mantuvieron su vigencia e interés a lo largo de la Modernidad.

Podo después, el arquitecto Manuel Reguera (Candás, Asturias, 1731- Oviedo, 1798), formado junto a Menéndez y su aparejador en la obra del hospicio, logró su titulación académica (1764) y se propuso imponer en Asturias el nuevo gusto artístico"11. Con este fin, denunció al maestro de la catedral de Oviedo, José Bernardo de la Meana (1715-1790), el mejor representante del barroco decorativo en la región, y entre sus acusaciones le reprochó el desconocimiento de los órdenes clásicos, pues "siendo la parte principal en que comúnmente se ejercitan las cinco órdenes de arquitectura, no se verifica haya adaptado y puesto en obra alguna de ellas con las reglas y elegancia que le corresponde" "112. Reguera no logró su objetivo de desplazar a Meana de los encargos arquitectónicos, pues éste también logró su titulación académica, pero en su escasa obra personal intentó mostrar su compromiso con la reforma mediante el empleo de tratados o la adaptación de prototipos castizos de innegable trascendencia clásica.

En el primero de los casos destaca el palacio que erigió para Pedro Velarde en Oviedo (1765-1770),

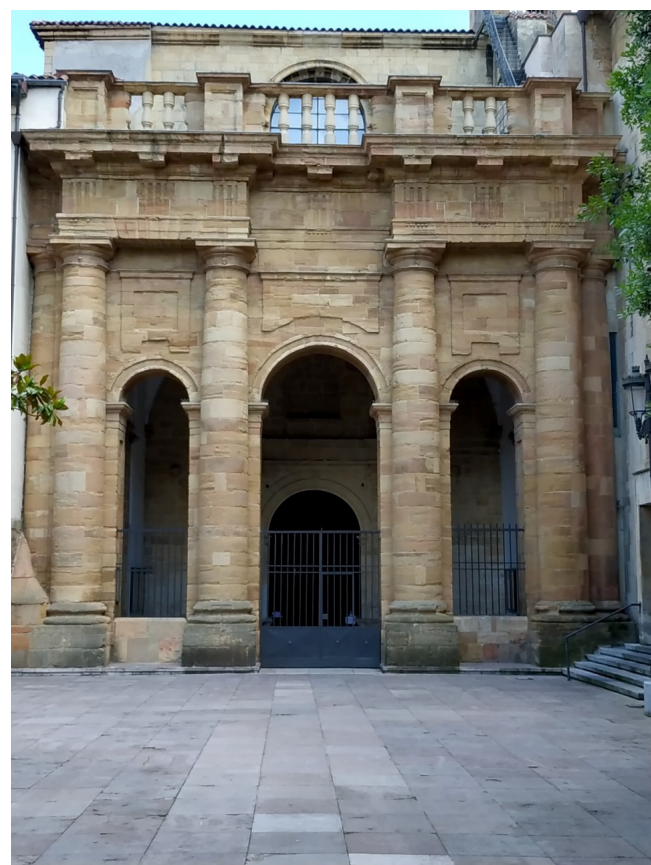

Fig. 20. Iglesia del convento de Santo Domingo de Oviedo. Pórtico (1767)

concebido como un auténtico prototipo reformista, donde plasma algunos asuntos ilustrados por Vignola, como los motivos de las metopas del orden dórico, que utiliza en el friso de la entrada, o la ventana del palacio de Caprarola, con la finalidad de actualizar un tipo arquitectónico tradicional|13. En el segundo caso, se encuentra el pórtico de la iglesia del convento de Santo Domingo de Oviedo (1767), que se inspira en la fachada principal de la catedral de Valladolid ${ }^{114}$ (fig. 20). Con este proyecto Reguera se incorporó a la corriente académica que postulaba la recuperación de la obra de Juan de Herrera como propuesta clasicista autóctona al servicio de la reforma ilustrada115, aunque probablemente desconociera que la fachada del edificio vallisoletano no se ajustaba a la idea inicial del arquitecto de El Escorial. En cualquier caso, el retorno a Herrera y a su escuela que efectuaron tanto Menéndez como Reguera evidencia no sólo su conocimiento de las corrientes artísticas contemporáneas, sino también la vigencia de una propuesta artística de carácter clasicista, que había arraigado con fuerza en la sensibilidad arquitectónica asturiana desde el siglo XVI. 


\section{NOTAS}

1 Ramallo Asensio, Germán. 1995. "Una base de mesura y dignidad arquitectónicas." In Madrid Álvarez, Vidal de la, La arquitectura de la Ilustración en Asturias. Manuel Reguera 1731 1798, 13-17. Oviedo: Real Instituto de Estudios Asturianos.

2 La reflexión sobre el carácter de la arquitectura de la Edad Moderna en Asturias tuvo su primer episodio a finales del siglo XIX con el ensayo de Fortunato de Selgas sobre las construcciones greco-romanas de la región. En su opinión, los edificios asturianos de estos siglos no mostraron la inclinación hacia el barroquismo característica de otros lugares de España a causa de "la oposición que ha habido siempre en Asturias a aceptar toda arquitectura decorativa, como sucede con el gótico, el plateresco y el churriguerismo, en los cuales la riqueza de ornatos y la profusión de detalles, borran las líneas arquitectónicas que dan majestad y grandeza al monumento". Sin embargo, Selgas no valora esta constante como una voluntad artística, sino como el resultado de unas cuestionables limitaciones creativas caracterizadas por "la timidez, encogimiento y falta de inventiva". Selgas, Fortunato de. 1882. "La arquitectura greco-romana en Asturias." Revista de Asturias, $\mathrm{n}^{\circ}$ 2: 17-23. También Selgas, Fortunato de. 1880. "Breves indicaciones sobre la arquitectura en Asturias." Revista de Asturias, $n^{\circ}$ 16: 247-251.

3 Trelles Villademoros, José Manuel. 1760. Asturias Ilustrada. Primitivo origen de la nobleza en España, su antigüedad, clases, y diferencias, con la descendencia sucesiva de las principales familias del reyno, t. III, 292. Madrid.

4 González Sánchez, Irma. 2004. "Patrimonio económico de la nobleza en el Gijón del siglo XVIII." In Faya Díaz, María Ángeles (coord.), La nobleza en la Asturias del Antiguo Régimen, 204-205. Oviedo: KRK Ediciones. Puede consultarse un documentado estudio de la familia en González Sánchez, Irma. 2009. LoS Valdés, una casa nobiliaria en el Gijón de los siglos XVI y XVII. Oviedo: KRK Ediciones. Véase también la semblanza de Juan Valdés publicada en Díaz Álvarez, Juan. 2012. "Arquitectura manierista asturiana: el Palacio Valdés de Gijón." Liño, $n^{\circ}$ 18: 45.

5 Juan de Valdés aparece en las mandas testamentarias del arzobispo de Sevilla; véase González Novalín, José Luis. 1971. El Inquisidor General Fernando de Valdés 1483-1568. Cartas y documentos, 382. Oviedo, Universidad de Oviedo.

6 Acerca de la trayectoria artística de Juan Bautista Portigiani resulta imprescindible la consulta del estudio que el profesor González Santos dedicó a este arquitecto, escultor y orfebre florentino, donde se actualiza y repasa su actividad conocida en la península hasta ese momento; véase González Santos, Javier. 1986. "El escultor florentino Juan Bautista Portigiani. Noticias de sus obras en Asturias." BSAA, $n^{\circ}$ 52: 297-310.

7 Desde finales de los años setenta, la historiografía artística regional se ha ocupado con frecuencia de las casas de Valdés, poniendo de relieve su singularidad en el panorama regional y su marcada influencia sobre las construcciones posteriores. Sin embargo, hasta hace pocos años no ha sido posible aclarar su proceso constructivo, ni la personalidad de sus autores. La secuencia de estas aportaciones ha sido como sigue. El profesor Ramallo Asensio fue el primero en destacar su interés cuando en 1978 escribió que era "una de las obras más perfectas de toda la arquitectura civil asturiana y modélica en su concepción de volúmenes, ordenación y revestimiento decorativo". Sin embargo, aunque advierte en ella aspectos del siglo $X V I$, a falta de una documentación precisa, la sitúa en el primer tercio del siglo XVII (Ramallo Asensio, Germán. 1978. La arquitectura civil asturiana (Época Moderna), 36-37 y 119-120. Salinas: Ayalga Ediciones). Poco tiempo después, Ramallo describió esta construcción como una "obra señera del clasicismo en Asturias y espejo y modelo para muchos otros palacios", ajustó su cronología a principios del siglo XVII y planteó la autoría de un "arquitecto intelectual" (Ramallo Asensio, Germán. 1981. "El Barroco." In AA. W., Arte Asturiano II (del Barroco a la actualidad), 22. Gijón: Silverio Cañada). Más tarde, profundizó en el análisis del diseño, sugirió que la erección del palacio hubiese precedido a la capilla y demostró el origen serliano de sus recursos compositivos (Ramallo Asensio, Germán. 1992. "El particular caso de las capillas palaciegas en la arquitectura barroca asturiana." In AA. VV., Actas VII CEHA, 362-363 y 365. Murcia: Universidad de Murcia y Ramallo Asensio, Germán. 1993. "El palacio urbano en Asturias." In Ramallo Asensio, Germán (coord.), Arquitectura señorial en el norte de España, 86-88. Oviedo: Universidad de Oviedo). Algún tiempo más tarde, relacioné la obra con las construcciones renacentistas de la centuria anterior y planteé la posibilidad de la intervención de Juan de Naveda, que se ha revelado infructuosa, aunque Losada Varea no la descartó en su monografía sobre el arquitecto montañés (Madrid Álvarez, Vidal de la. 1996. "Arquitectura barroca civil." In Barón Thaidigsmann, Javier (dir.), El arte en Asturias a través de sus obras, 207-210. Oviedo: Prensa Asturiana; Losada Varea, Celestina. 2007. La arquitectura en el otoño del Renacimiento. Juan de Naveda, 321-322. Santander: Universidad de (antabria). Por esas mismas fechas García Cuetos sugirió la intervención del arquitecto Juan de Cerecedo el Viejo en las obras de una vivienda que sería anterior a la actual y estaría datada en torno a los años sesenta del siglo XVI (García Cuetos, María Pilar. 1996. Arquitectura en Asturias 1500-1580. La dinastía de los Cerecedo, 94-95. Oviedo: Real Instituto de Estudios Asturianos). Por fin, en 2005 Sampedro Redondo aclaró definitivamente la cuestión de la autoría de la fachada del palacio tras publicar las condiciones de la obra firmadas por Juan Bautista Portigiani (Sampedro Redondo, Laura. 2005. "Sobre la autoría del palacio de los Valdés en Gijón: de Juan de Cerecedo, el viejo, a Juan Bautista Portigiani." De Arte, n 4: 55-62). Finalmente, González Santos y Díaz Álvarez aclararon la fecha y la autoría de la capilla (González Santos, Javier. 2000. "Les Artes n'Asturies en tiempo d'Anton de Marirreguera." In AA. VV., Anton de Marirreguera y el Barrocu Asturianu, 96. Oviedo: Principado de Asturias; Díaz Álvarez, Juan. 2012. "Arquitectura manierista asturiana: el Palacio Valdés de Gijón." Liño, n 18: 43-55).

8 García Cuetos, Arquitectura, 9495. 
9 Sampedro Redondo, "Sobre la autoría", 55-62.

10 Caravita, Andrea. 1871. I codici e le arti a Monte Cassino, vol. III, 122 y 129. Monte Cassino.

11 En 1568 Portigiani contrató el dorado y pintura de este retablo con el pintor Benito Rabuyate tomando como fiador al escultor Juan de Juni. A causa de algunas desacuerdos sobre la obra, Rabuyate entabló pleito contra ambos en 1570 y logró un fallo favorable en 1572. Sobre esta obra véase González Santos, "El escultor florentino", 298299.

12 González Santos, "El escultor florentino", 299 y 303-306.

13 En opinión de Cadiñanos Bardeci "La documentación deja bien claro que la idea general para la construcción de estos arcos se debió a Pompeyo Leoni, aunque llevada a cabo por su aparejador Juan Bautista Portigiani (o Portiguiani)" y, además, "Leoni alegó que a él sólo le tocaba dar la traza y orden que debía llevar el arco, pero la ejecución, oficiales, materiales y pagos correspondía a la villa, como exponía el contrato. Pudo demostrar que Juan Bautista Portigiani había asistido continuamente a todo, en su nombre. Y, junto a él, habían trabajado Mateo Vicencio, Mateo Baral y el platero Estacio de Sevilla.", en Cadiñanos Bardeci, Inocencio. 1998. "Pompeyo Leoni y los arcos de la entrada triunfal de Doña Ana de Austria." Boletín de la Real Academia de Bellas Artes de San Fernando, n 86: 180, 182 y 187. Véase también Velázquez Soriano, Isabel, Consuelo Gómez López, Antonio Espigares Pinilla y Ana Jiménez Garnica. 2007. La relación de la entrada triunfal de Ana de Austria en Madrid de Juan López de Hoyos. Estudios, edición, crítica y notas, 33. Madrid: Universidad Complutense de Madrid. En este estudio, los autores consideran a Sebastián Serlio la fuente de inspiración fundamental para el diseño de los arcos triunfales erigidos en los festejos.

14 "el 14 de octubre se contrató con Juan Bautista Portijano, extranjero (Portigiani en su firma) la ejecución de un castillo, que se especificaba habrá de ser de madera canteada por fuera de color de piedra berroqueña, con planta cuadrada de 30 pies de lado", Cruz Val- dovinos, José Manuel. 1990. "La entrada de la reina Ana en Madrid en 1570." Anales del Instituto de Estudios Madrileños, n 28: 424.

15 González Santos, "El escultor florentino", 300; Estella Marcos, Margarita. 1990. Juan Bautista Vázquez el viejo en Castilla y América, 13-14 y 8081. Madrid: CSIC; Ceán Bermúdez, Juan Agustín. 1800. Diccionario histórico de los más ilustres profesores de las Bellas Artes en España, t. II, 271, t. IV, 115 y t. V, 207. Madrid: Real Academia de San Fernando; Pérez Sedano, Francisco. 1914. Datos documentales inéditos para la Historia del Arte Español I. Notas del archivo de la catedral de Toledo, redactadas sistemáticamente, en el siglo XVIII, por el canónigo-obrero don .... 115. Madrid; Marías, Fernando. 2018. "Nicolás de Vergara el viejo y la lámpara de plata del Escorial." In Cañestro Donoso, Alejandro (coord.), Scripta artivm in honorem Prof. José Manuel Cruz Valdovinos, 167. Alicante: Universidad de Alicante.

16 "En 7 de enero de 1574. Carta a las justicias de Villamayor para que permitiesen a Juan Bautista Portiguiani y Francisco de Acosta beneficiar la mina llamada del Viejo, término de dicha villa; dando fianzas de que si alguna persona tuviese derecho a ella, estarían con el á partido guardando las leyes y ordenanzas de minas del reino, y llamando las partes a quien tocare hiciesen justicia". González Carvajal, Tomás. 1832. Registro y relación general de minas de la corona de Castilla. Primera parte. Comprende los registros, relaciones y despachos tocantes a minas, en que se expresan los pueblos y sitios en que se hallaron, t. I, 687. [Madrid].

17 Marías, Fernando. 1983. La arquitectura del Renacimiento en Toledo (1541-1631), t. I, 165-175. Toledo: Instituto Provincial de Investigaciones y Estudios Toledanos y Marías, Fernando. 1989. El largo siglo XVI, 376-385. Madrid: Taurus.

$18 \mathrm{El}$ contrato del comitente con el maestro Helguera de 3 de mayo de 1564 precisa que "Juan Battista, arquitecto ytaliano, abía dado oy dicho día otra nueba traza para que conforme a ella, se hiziesen, traçasen y hedificasen las dichas casas". Sin embargo, las condiciones elaboradas por Portigiani tan sólo describen la forma de realizar la fachada y, especialmente, las puertas, ventanas y saeteras del edificio, que deben acomodarse a "la planta y montea y debuxo que hiço Juan Batysta, que queda en poder del dicho Juan de Baldés, y todas la puertas y bentanas se arán conforme al debuxo". Pueden consultarse estos documentos en Sampedro Redondo, "Sobre la autoría", 58-60.

19 Acerca de la serliana véase Marías, Fernando. 1992. "Los sintagmas clásicos en la arquitectura española del siglo XVI." In AA. WV., L'emploi des ordres dans l'architecture de la Renaissance, 247-261. París: Picard y Parada López de Corselas, Manuel. 2018. "La serliana del palacio de Carlos V en Granada: Arquitectura del poder entre España e Italia". In Galera, Pedro A. y Sabine Frommel (eds.), El patio circular en la arquitectura del Renacimiento. De la casa de Mantegna al palacio de Carlos V, 151-192. Sevilla: Universidad Internacional de Andalucía.

20 Sobre el tratado de Serlio véase Sambricio, Carlos. 1986. "La fortuna de Sebastiano Serlio." In Serlio de Bolonia, Sebastián, Todas las obras de arquitectura y perspectiva de ..., 7-135. Oviedo: Colegio Oficial de Aparejadores y Arquitectos Técnicos de Asturias.

21 Marías, La arquitectura del Renacimiento, 51

22 La documentación publicada por Díaz Álvarez demuestra que Pedro de Cubas de la Huerta elaboró trazas propias para la obra; véase Díaz Álvarez, "Arquitectura manierista", 49.

23 Madrid Álvarez, Vidal de la. 2007. "Arte y mecenazgo indiano en la Asturias del Antiguo Régimen". In Sazatornil Ruiz, Luis (ed.), Arte y mecenazgo indiano. Del Cantábrico al Caribe, 322326. Gijón: Ediciones Trea.

24 Díaz Álvarez, "Arquitectura manierista", 47.

25 Díaz Álvarez, "Arquitectura manierista", 52. Sobre la capilla de la Concepción véase Pedrayes Obaya, Juan José. 1990. "La capilla de la Concepción de Villaviciosa: una obra desconocida de Juan de Naveda." Boletín Académico, $\mathrm{n}^{\circ}$ 12: 10-14.

26 Ramallo Asensio, "El particular caso", 365. 
27 Cuando Gutierre Bernardo de Quirós y Las Alas Carreño (†1699), primer marqués de Camposagrado, contrató en 1693 la erección de la fachada meridional de su palacio de Avilés estableció que todos los huecos debían mostrar enmarcaciones de aparejo rústico reproduciendo lo realizado en Gijón más de un siglo antes: "Ha de ser todo de la misma fábrica y moldura de almohadado de la forma que está labrada la casa de Don Pedro Valdés de Jijón"; véanse Ramallo Asensio, Germán. 1983. "Las casas urbanas de la familia Camposagrado." In AA. VV., /l Simposio sobre el padre Feijoo y su siglo, t. II, 575-592. Oviedo: Centro de Estudios del siglo XVIII; Madrid Álvarez, Vidal de la. 2010. "El palacio del marqués de Camposagrado en Avilés (Asturias) y la muralla de la villa a finales del siglo XVII." Liño, $n^{\circ}$ 16: 67-83; y Madrid Álvarez, Vidal de la. 2018. Los Menéndez Camina y la arquitectura barroca en Asturias, 168-170. Gijón: Trea.

28 "La llegada del purismo clasicista a la región asturiana se produjo a través de dos vías, en cierto modo interrelacionadas: el legado valdesiano y las obras llevadas a cabo por las órdenes religiosas, desarrollándose una actividad constructiva continuada que nos dejó obras tan destacadas como la Universidad de Oviedo o la iglesia de S. Juan de Corias", Pastor Criado, María Isabel. 1991. "Las vías de penetración del purismo clasicista en Asturias y su proyección." Príncipe de Viana. Anejo, n 12: 258. El papel trascendente jugado por la orden benedictina para la implantación del clasicismo en la región ha sido estudiado por vez primera en Ramallo Asensio, Germán. 1982. "Los monasterios benedictinos como promotores de la evolución artística en Asturias." In AA. V., Semana de historia del monacato cántabro-astur-leonés, 421-453. Oviedo: Monasterio de San Pelayo.

29 Miguel Vigil fue el primero en vincular documentalmente a Rodrigo Gil de Hontañón y a Juan del Ribero con la obra de la universidad ovetense en estos términos: "Por escritura otorgada el año de 1572 ante el Escribano de Oviedo Alonso de Heredia, se remata la importantísima obra de la Universidad literaria en favor de Rodrigo Gil, quien nombró por encargado y representante suyo por contrato de 10 de Julio de 1575 a Juan del Rivero, natural de León y maestro de las obras de la Catedral de Salamanca" (Miguel Vigil, Ciriaco. 1889. Colección Histórico-Diplomática del Ayuntamiento de Oviedo, 458. Oviedo). Unos años después, Canella Secades recogió esta información al mencionar a Rodrigo Gil como responsable de la obra y a Juan del Rivero como director de los trabajos y rematante en su nombre (Canella Secades, Fermín. 1903. Historia de la Universidad de Oviedo y noticias de los establecimientos de enseñanza de su distrito (Asturias y León), 28. Oviedo). En fechas más recientes, Ramallo Asensio atribuyó la autoría de la obra a Juan del Ribero como "absoluto responsable del aspecto material del edificio" (RamaIlo Asensio, Germán. 1981. "El Renacimiento." In AA. VV., Arte Asturiano II (del Barroco a la actualidad), 337. Gijón: Silverio Cañada; véase también Ramallo, La arquitectura civil, 89-90). Al año siguiente, Javier Rivera afirmó que Ribero se ocupó de la obra hasta 1600 "debiéndose a su traza, sin duda alguna, el claustro" (Rivera Blanco, Javier. 1982. La arquitectura de la segunda mitad del siglo XVI en la ciudad de León, 48-49. León: Institución "Fray Bernardino de Sahagún" y Consejo Superior de Investigaciones Científicas). Por su parte, Pastor Criado, autora de un documentado estudio sobre la arquitectura clasicista en Asturias, asignó la autoría del conjunto a Rodrigo Gil como responsable de las trazas iniciales de la obra, pero esta propuesta fue cuestionada por los profesores Casaseca y García Cuetos, pues consideraron que el edificio actual no se ajustaba al estilo del maestro madrileño (Pastor Criado, María Isabel. 1987. Arquitectura purista en Asturias, 65 y 95. Oviedo, Principado de Asturias; Casaseca Casaseca, Antonio. 1988. Rodrigo Gil de Hontañón (Rascafría 1500-Segovia 1577), 239. Salamanca: Juan de Castilla y León; García Cuetos, Arquitectura, 219-223). Finalmente, la profesora Faya Díaz publicó en 2004 y 2008 unos interesantísimos documentos, hasta entonces inéditos, sobre el desarrollo de los trabajos del edificio universitario, que incluyen las condiciones de obra iniciales del proyecto de Rodrigo Gil y la condiciones de obra de las reformas ordenadas por Juan Osorio. Esta documenta- ción ha contribuido a clarificar el debate, pero no ha permitido despejar todas las dudas (Faya Díaz, María Ángeles. 2004. "Los Valdés Salas y la fundación de la Universidad de Oviedo." In Faya Díaz, María Ángeles (coord.), La nobleza en la Asturias del Antiguo Régimen, 147197. Oviedo: KRK Ediciones y Faya Díaz, María Ángeles. 2008. "La fundación de la Universidad. Las memorias y obras pías del arzobispo Fernando de Valdés y sus vicisitudes." In Uría, Jorge, Carmen García y Aida Terrón (eds.), Historia de la Universidad de Oviedo, vol. I, 35-81 y 255-273. Oviedo: Universidad de Oviedo).

30 Faya Díaz, "La fundación", p. 37. Sobre Fernando Valdés debe consultarse González Novalín, José Luis. 1971. El Inquisidor General Fernando de Valdés (1483-1568), 2 vols. Oviedo: Universidad de Oviedo.

31 Acerca de su inmensa fortuna escribió Fermín Canella que sus rentas "le hicieron tan rico y opulento que, a no constar de su última voluntad y fundaciones, se creería fabulosa la magnitud de sus riquezas", Canella Secades, Historia de la Universidad, 17. Faya Díaz, por su parte, reconoce la dificultad para calcular con exactitud la magnitud de su fortuna, pero recoge un memorial donde se cuantifica en 917.000 ducados el valor de los bienes y hacienda que dejó a su muerte, Faya Díaz, "Los Valdés Salas", 152-153.

32 Faya Díaz, "Los Valdés Salas", 171.

33 Faya Díaz, "Los Valdés Salas", 173-174. Sobre Rodrigo Gil de Hontañón véanse, al menos, Hoag, John D. 1985. Rodrigo Gil de Hontañón. Gótico y Renacimiento en la arquitectura española del siglo XVI. Madrid: Xarait Ediciones y Casaseca Casaseca, Rodrigo Gil. Juan del Ribero, por su parte, carece aún de un estudio monográfico general de su obra, pero cuenta con numerosas publicaciones entre las que reseñamos las siguientes: Rivera Blanco, La arquitectura; Bustamante García, Agustín. 1983. La arquitectura clasicista del foco vallisoletano (1561-1640), 88-101. Valladolid: Institución Cultural Simancas; Rodríguez G. de Ceballos, Alfonso y Antonio Casaseca. 1986. "Juan del Ribero Rada y la introducción del clasicismo en 
Salamanca y Zamora." In AA. W., Herrera y el Clasicismo, 95-109. Valladolid: Junta de Castilla y León; Rodríguez G. de Ceballos, Alfonso. 1986. "La librería del arquitecto Juan del Ribero Rada." Academia, n 62: 121-154; González Echegaray, María del Carmen, Miguel Ángel Aramburu-Zabala Higuera, Begoña Alonso Ruiz y Julio J. Polo Sánchez. 1991. Artistas cántabros de la Edad Moderna. Su aportación al arte hispánico, 563-569. [Santander]: Institución Mazarrasa y Universidad de Cantabria; Muñoz Jiménez, José Miguel. 1993. "Juan del Ribero Rada (1540-1600), arquitecto palladiano y antiherreriano." Historias de Cantabria, $\mathrm{n}^{\circ}$ 6: 24-62; Campos Sánchez-Bordona, María Dolores. 1994. "Los órdenes clásicos en la arquitectura de Juan del Ribero Rada." In AA. Vv., Actas del X Congreso del CEHA. Los clasicismos en el arte español, 467474. Madrid: UNED; Campos SánchezBordona, María Dolores. 1995. "Juan del Ribero Rada y el orden dórico." Academia, $n^{\circ}$ 81: 517-541; Campos Sánchez-Bordona, María Dolores. 1996. "Juan del Ribero Rada. Arquitecto clasicista." Altamira, n 52: 127-166; Campos Sánchez-Bordona, María Dolores. 2002. "Arte y cultura en la biblioteca de Juan del Ribero Rada." In Nieto Ibáñez, Jesús María, Humanismo y Tradición Clásica en España y América, 311-332. León: Universidad de León; Palladio, Andrea. 2003. Los cuatro libros de Arquitectura de Andrea Palladio, traducidos del italiano al castellano por Juan del Ribero Rada, estudio introductorio, edición y notas de María Dolores Campos Sánchez-Bordona. Salamanca: Junta de Castilla y León y Universidad de León.

34 Sobre este asunto véanse: Rivera Blanco, La arquitectura, 179-180; Campos Sánchez-Bordona, "Juan del Ribero", 133-134 y Campos SánchezBordona, María Dolores. 2007. "Las transformaciones de la arquitectura señorial del renacimiento español, como reflejo del devenir histórico y del debate de las teorías restauradoras. El ejemplo del palacio de los Guzmanes de León." De Arte, n 6: 173-176.

35 Sobre el trasmerano Diego Vélez véanse Pastor Criado, Arquitectura purista, 185-186 y González Echegaray y otros, Artistas cántabros, 688-689.
36 García Cuetos, Arquitectura, 221. Véanse también Faya Díaz, "Los Valdés Salas", 175-179 y Faya Díaz, "La fundación", 48 y 69-70.

37 Para la documentación del proceso constructivo del edificio universitario deben consultarse Pastor Criado, Arquitectura purista, 64-85; García Cuetos, Arquitectura, 219-224; Faya Díaz, "Los Valdés Salas", 171-180 y Faya Díaz, "La fundación", 65-71.

38 Pastor Criado, Arquitectura purista, 74; García Cuetos, Arquitectura, 221; Faya Díaz, "Los Valdés Salas", 175176 y 179.

39 El texto completo de las condiciones del proyecto de Rodrigo Gil puede consultarse en Faya Díaz, "Los Valdés Salas", 191-197.

40 "Yten se ha de hacer la puerta prençipal con su guarniçion de colunas ganvas arco con dintel al rromano ansi en pedestrales vasas colunas capiteles y cornisa su moldura de la orden doricay que suva la portada todo el alto del primer suelo y ençima della se hara una bentana prençipal que suva ella y su ornato hasta en baxo del texariz a rrematar y concluir su frontispicio y que tenga a los lados de la venta ençima de las colunas de la portada sus dos hescudos de armas en cada pte el suyo de muy buen tamaño obra y ornato y que en el frontispicio dentro de su vaco aya un hepitafio", Faya Díaz, "Los Valdés Salas", 193.

41 El texto completo de las reformas ordenadas por Juan Osorio puede consultarse en Faya Díaz, "La fundación", 265-273.

42 "en lo alto del se han de hacer dos espexos por dende ente la luz a la dha capilla, muy bien echos que salgan a la parte de afuera asta tres dedos fuera del bibo de la parez de labor almoada y que sean las unas piedras mas largas que las otras vien echos por la orden rustica.", Faya Díaz, "La fundación", 269.

43 "conforme a la traça questo tiene del dho señor don Juan y de Diego Velez tampoco se altera en cosa ninguna mas de la forma de las puertas y ataxos que a de haber y ansi se seguira la traça que esta firmada de ambos a dos y mi escribano.", Faya Díaz, "La fundación", 271.
44 Esta posibilidad ya ha sido apuntada por el profesor Casaseca al relacionar el patio universitario con el claustro del monasterio de las Bernardas de Salamanca, que también muestra ritmo doble en los soportes del primer piso (Casaseca Casaseca, Rodrigo Gil, 239). Aunque existe algún ejemplo clasicista con ritmo doble en la planta superior como el bramantesco claustro de Santa María della Pace en Roma (1500), su diseño también se justifica como un arcaísmo o influjo medieval: "I porticati sono divisi in campate che raddoppiano nella parte superiore, dove pertanto compaiono sostegni in falso, situati in corrispondenza della sommità dell'arco sottostante. Si tratta di una soluzione ricorrente nella tradizione medievale lombarda: essa rispondeva alla funzione, tipica dell'architettura gotica e già messa in evidenza, di imporre un peso sulla mezzeria degli archi sottostanti a sesto acuto, allo scopo di contrastare la loro tendenza ad aprirsi in chiave. ॥ chiostro bramantesco, che pure rappresenta uno dei primi e principali esempi del ritorno all'antico, fu risolto in forme che contraddiccevano il principio classico della corrispondenza fra pieni e vuoti, fra l'altro enunciato anche da Leon Alberti.", Simoncini, Giorgio. 2016. La memoria del medioevo: nell'architettura dei secoli XV-XVIII, 136-137. Roma: Gangemi Editore.

45 Pastor Criado, Arquitectura purista, 87, Campos Sánchez-Bordona, "Los órdenes clásicos", 469 y Campos Sánchez-Bordona, "Juan del Ribero Rada y el orden dórico", 530-533.

46 Véanse Rodríguez G. de Ceballos y Casaseca, "Juan del Ribero", 101 y Campos Sánchez-Bordona, "Juan del Ribero Rada", 139-140.

47 Sobre Domingo de Mortera y su obra véanse Pastor Criado, Arquitectura Purista, 70-78, 151-153, 168-172 y 190-192; González Echegaray y otros, Artistas cántabros, 441-442; Cagigas Aberasturi, Ana, Miguel Ángel Aramburu-Zabala Higuera y Luis de Escallada González. 2001. Los maestros canteros de Ribamontán, 75-76. Ayuntamiento de Ribamontán al Mar y Ayuntamiento de Ribamontán al Monte; Kawamura, Yayoi. 2006. Arquitectura y poderes civiles. Oviedo 1600-1680, 27, 157 y 171. Oviedo: RIDEA y Kawamura, Yayoi. 
2010. "El arquitecto Domingo de Mortera: acerca de su biblioteca y sus últimos trabajos." BSAA arte, $n^{\circ}$ 76: 71-80.

48 Kawamura, Yayoi, "El arquitecto Domingo", 74-78.

49 Pastor Criado, Arquitectura purista, 151-153. Sobre Güemes Bracamonte puede consultarse González Echegaray y otros, Artistas cántabros, 284.

50 Claustro del monasterio de Belmonte en Quadrado, José María. 1855. Recuerdos y Bellezas de España. Asturias y León, entre las páginas 226-227. Madrid.

51 Pastor Criado, Arquitectura Purista, 168-172.

52 Acerca de la reforma impulsada por la Congregación de San Benito de Valladolid véase García Oro, José. 1979. "Conventualismo y observancia." In García-Villoslada, Ricardo (dir.), Historia de la Iglesia en España, vol. 3, t. 1, 211-350. Madrid: BAC. Para el caso asturiano véase Fernández Conde, Javier. 1999. "Centralismo y reforma en los monasterios benedictinos asturianos a finales de la Edad Media: Implantación de la Congregación de la Observancia de San Benito de Valladolid." In Aragón en la Edad Media, n 14-15: 509520 y Ramallo Asensio, Germán, "Los monasterios benedictinos", 421-453 . El protagonismo alcanzado por Juan del Ribero en la extensión del modelo clásico vinculado a la reforma de estas congregaciones ha sido estudiado en Campos Sánchez-Bordona, María Dolores. 2012. "Juan del Ribero Rada. Intérprete e impulsor del modelo clasicista en la arquitectura monástica benedictina." BSAA arte, $\mathrm{n}^{\circ}$ 78: 19-44.

53 Campos Sánchez-Bordona, "Juan del Ribero Rada. Intérprete", 1944.

54 Yepes afirma que la anexión de la abadía de San Vicente de Oviedo a la Congregación de San Benito tuvo lugar mediante una bula expedida por el pontífice León X(1513-†1521) en 1515, pero no se hizo efectiva hasta 1517; véase Yepes, Antonio de. 1610. Coronica General de la Orden de San Benito, Patriarca de Religiosos, t. III, 233. Universidad de Nuestra Señora de Irache.

55 El profesor Ramallo Asensio estudió las transformaciones renacentistas del monasterio de San Vicente como parte del impulso renovador que las comunidades benedictinas proporcionaron al arte asturiano de la época. En su análisis atribuyó la planta baja del claustro a Juan de Badajoz el Mozo (†1554) relacionó a Juan de Cerecedo el Joven con el primer impulso constructivo de la iglesia y sugirió la intervención de Juan del Ribero en su conclusión, aunque sin descartar a Juan de Tolosa (Ramallo Asensio, "Los monasterios benedictinos", 424-434; Ramallo Asensio, "El Renacimiento", 316-319 y 326-328). Posteriormente, la profesora Fernández del Hoyo documentó la intervención de Juan del Ribero en la iglesia mediante un contrato suscrito entre el maestro y el abad fray Pedro de Agüero en Valladolid (Fernández del Hoyo, María Antonia. 1983. "Juan del Ribero y la iglesia monasterial de San Vicente de Oviedo", Astura, $n^{\circ}$ 1: 69-70). Pastor Criado, por su parte, confirmó la relación de los Cerecedo con la obra de San Vicente-Juan de Cerecedo, el Joven se encontraba trabajando para el monasterio en 1571y profundizó en el análisis de la intervención de Ribero en la iglesia (Pastor Criado, Arquitectura purista, 124-133). Por último, García Cuetos documentó la autoría de Juan de Cerecedo el Viejo del primer proyecto de la iglesia y le atribuyó la planta superior del claustro (García Cuetos, Arquitectura, 164-169).

56 Pastor Criado, Arquitectura purista, 125 y García Cuetos, Arquitectura, 164-165.

57 Sobre los diseños de Ribero para la reconstrucción del monasterio de San Benito de Valladolid véase AA. V., Herrera y el Clasicismo, 215-219. Véase también Rivera, Javier (coord.). 1990. Monasterio de San Benito el Real de Valladolid VI Centenario 1390-1990. Valladolid: Ayuntamiento de Valladolid, INEM y Escuela-taller Monasterio de San Benito.

58 Ramallo Asensio, "El Renacimiento", 326 y Fernández del Hoyo, "Juan del Ribero", 69.

59 Esa analogía ya ha sido mencionada por Isabel Pastor (Pastor Criado, Arquitectura purista, 131). Sobre la portada del priorato de San Isidoro véase Rivera Blanco, La arquitectura, 138-142. Campos Sánchez-Bordona, por su parte, relacionó esta portada también con la de la hospedería del monasterio de Santa Espina (1576-78) en Valladolid, donde se combinan las columnas jónicas en la calle central con las pilastras de este orden en las laterales, e identificó en estas estructuras un sentido volumétrico y escultórico que, en su opinión, distingue la obra de Ribero de la propuesta de Juan de Herrera, más severa y desornamentada (Campos Sánchez-Bordona, Juan del Ribero Rada, 139-140).

60 Pastor Criado, Isabel. 1996. "Arquitectura de la segunda mitad del siglo XVI." In Barón Thaidigsmann, Javier, El arte en Asturias a través de sus obras, 192-194. Oviedo: Prensa Asturiana.

61 Según Antonio Yepes, la anexión de la abadía de San Juan de Corias a la Congregación de San Benito tuvo lugar mediante una bula expedida por el pontífice Paulo III (1534-†1549) en 1536; véase Yepes, Antonio de. 1617. Coronica General de la Orden de San Benito, Patriarca de Religiosos, t. VI, 23. Valladolid.

62 Apenas contamos con documentación fidedigna sobre el proceso constructivo de la iglesia del monasterio de San Juan de Corias, por lo que siguen citándose las informaciones proporcionadas por Justo Cuervo, quien en 1894 afirmó haber leído un manuscrito que certificaba el inicio de las obras en 1593, durante el gobierno del abad Antonio Yepes, y su conclusión en 1604, aunque, curiosamente, también recoge una noticia que demora la bendición de la "iglesia nueva" hasta 1650 (Cuervo, Justo. 1894. "El monasterio de San Juan de Corias". In Bellmunt y Traver, Octavio y Fermín Canella y Secades, Asturias, t. I, 227. Gijón). Por su parte, el profesor Ramallo Asensio abordó el análisis de este templo, en su opinión, "el mejor y más grandioso ejemplo de arquitectura clasicista de toda Asturias", como una manifestación destacada de la renovación artística emprendida por los cenobios benedictinos a finales del siglo XVI, pero no plantea la autoría de Ribero (Ramallo Asensio, Germán. 1981. "La zona suroccidental asturiana: Tineo, Cangas del Narcea, Allande, Ibias y Degaña" Liño, $n^{\circ}$ 2: 228-233; Ramallo Asensio, "Los monasterios benedictinos", 434443; Ramallo Asensio, "El Renacimiento", 329-330). Años más tarde, Pastor 
Criado documentó a Ribero como autor de las trazas del claustro y le atribuyó el proyecto del templo (Pastor Criado, Arquitectura purista, 137-144). Recientemente, Alejandro García ha efectuado un estudio de conjunto del monasterio aportando datos procedentes de las investigaciones arqueológicas realizadas durante el proceso de restauración (García Álvarez-Busto, Alejandro. 2016. Arqueología de la arquitectura monástica en Asturias: San Juan Bautista de Corias. Oviedo: Consejería de Educación y Cultura del Principado de Asturias).

63 Pastor Criado, Arquitectura purista, 137-138.

64 Sobre la reconstrucción del monasterio véase Morales Saro, María Cruz. 1978. "Datos sobre la construcción del monasterio de Corias (Cangas del Narcea)." Boletín del Instituto de Estudios Asturianos, n 93-94: 295-313.

65 Cuervo, "El monasterio", 227. Antonio Yepes afirma que la iglesia medieval se había arruinado en 1568 (Yepes, Coronica General, t. VI, 21).

66 Pastor Criado, Arquitectura purista, 140-141 y Fernández Martín, Luis. 1985. "Domingo de Argos, constructor de la iglesia de San Juan de Corias." Astura, $n^{\circ}$ 4: 79-83. Sobre Domingo de Argos véanse Pastor Criado, Arquitectura purista, 187-188 y González Echegaray y otros, Artistas cántabros, 688-689, 52-53.

67 La atribución a Juan del Ribero fue propuesta por Isabel Pastor (Pastor Criado, Arquitectura purista, 139-140).

68 Ramallo Asensio, "Los monasterios benedictinos", 437-438.

69 "Ribero Rada comienza a desarrollar un tipo de portada muy elegante e italiano, formado por un arco de triunfo, columnas pareadas, entablamento y balcón. Este modelo, donde primero aparece es en San Isidoro de León", Bustamante García, La arquitectura clasicista, 549 .

70 Sobre Juan de Tolosa véanse Llaguno y Amirola, Eugenio y Ceán Bermúdez. Juan Agustín. 1977. Noticias de los arquitectos y arquitectura de España desde su Restauración, t. I, 7980. Madrid: Ediciones Turner (reedición de la de Madrid, Imprenta Real, 1829); Bonet Correa, Antonio. 1984. La arquitectura en Galicia durante el siglo xvii,
177-193. Madrid: CSIC (reimpresión de la de Madrid, 1966); Bustamante García, La arquitectura clasicista, 325-332; Rodríguez Gutiérrez de Ceballos, Alfonso. 1966. "Juan de Herrera y los jesuitas Villalpando, Valeriani, Ruiz, Tolosa." Archivum Historicum Societatis lesu, n 35: 285-321 y Ferro Couselo, Jesús. 1971. "Las obras del colegio e iglesia de Montederramo en los siglos xvi y xvii." Boletín Auriense, $n^{\circ}$ 1: 148.

71 Sobre la fundadora pueden consultarse Villafañe, Juan de. [1723]. La Limosnera de Dios. Relación histórica de la vida, y virtudes de la excelentísima señora Doña Magdalena de Ulloa Toledo Ossorio y Quiñones, mujer del Excelentíssimo señor Luis Méndez Quixada Manuel de Figueredo y Mendoza. Salamanca; Abad, Camilo María. 1959. Doña Magdalena de Ulloa. La educadora de don Juan de Austria y fundadora del colegio de la Compañía de Jesús de Villagarcía de Campos (1525-1598). Comillas: Universidad Pontificia de Comillas y AA. VV. 1998. Doña Magdalena de Ulloa, mujer de Luis Quixada (1598-1998). Una mujer de Villagarcía de Campos (Valladolid). Su profundo influjo social. Valladolid: Diputación de Valladolid. La fundación ovetense ha sido documentada en Patac, José María y Elviro Martínez. 1991. Historia del Colegio de San Matías de Oviedo. Gijón: Biblioteca Asturiana ( $2^{\circ}$ edición corregida y aumentada de la 1976) y García Sánchez, Justo. 1991. Los jesuitas en Asturias. Oviedo: IDEA.

72 Miguel Vigil, Colección históricodiplomática, 504.

73 El proceso constructivo del Colegio de San Matías de Oviedo ha sido estudiado por Ramallo Asensio, "El Renacimiento", 325-326 y "El Barroco", 20-21 y Pastor Criado, Arquitectura purista, 164-166.

74 Sobre las transformaciones barrocas de la iglesia véase Madrid Álvarez, Los Menéndez Camina, 98-113.

75 Acerca de los parentescos artísticos del templo véase Ramallo Asensio, "El Barroco", 20.

76 Sobre Juan de Naveda pueden consultarse los trabajos de Germán Ramallo Asensio: La Arquitectura Civil, 103-113; "El Barroco", 16-20; 1996. "Arquitectura Barroca Religiosa (I): La catedral de Oviedo."In Barón Thaidigs- mann, Javier (dir.), El arte en Asturias a través de sus obras, 230-234. Oviedo: Editorial Prensa Asturiana; 1999. "El Barroco". In Caso, Francisco de, Cosme Cuenca, César García de Castro, HEVIA, Jorge Hevia, Vidal de la Madrid y Germán Ramallo, La Catedral de Oviedo I. Historia y restauración, 140-163. Oviedo: Nobel. También suministran informaciones y análisis sobre la obra de Naveda: Muñoz Jiménez, José Miguel. 1985. "Juan de Naveda y la arquitectura del manierismo clasicista en la villa de Santander (1600-1630)." Altamira, $\mathrm{n}^{\circ}$ 45: 189-210; Muñoz Jiménez, José Miguel. 1992. "Reflexiones sobre la significación del arquitecto Juan de Naveda (1607-1640)." Historias de Cantabria, n 2: 7-21; Pedrayes Obaya, Juan José. 1990. "La capilla de la Concepción de Villaviciosa: una obra desconocida de Juan de Naveda." Boletín Académico, $\mathrm{n}^{\circ}$ 12: 10-14; Pedrayes Obaya, Juan José. 1996. "El arquitecto Juan de Naveda y la capilla de los Reyes Magos del Palacio de Villabona." Astura, n 10: 61-68; González Echegaray y otros, Artistas cántabros, 458-461; Madrid Álvarez, "Arquitectura barroca", 202-206; Caso, Francisco de. 2001. "Algunos datos documentales sobre la capilla de los Vigiles y su retablo." Astura, $n^{\circ}$ 11: 5765; Kawamura, Yayoi. 2003-2004. "Reflexión sobre el modelo del Panteón de Roma en la capilla del obispo Vigil de la catedral de Oviedo y otras precisiones." BSAA, n 69-70: 359-372; Kawamura, Arquitectura, 30-31 y 80-90; Losada Varea, La arquitectura en el otoño; Díaz Álvarez, Juan. 2007. "La obra del arquitecto Juan de Naveda o la recepción del Clasicismo Herreriano en la Asturias del primer tercio del siglo XVII". In Llordén Miñambres, Moisés y Juan Miguel Menéndez Llana (coords.), I Congreso de Estudios Asturianos, vol. 5, 31-49. Oviedo: RIDEA.

77 Sobre la formación de Juan de Naveda véase Losada Varea, La arquitectura en el otoño, 102-155.

78 "Francisco de Praves va a recoger toda la tradición clasicista iniciada en 1575 y la va mantener viva hasta su muerte", Bustamante García, La arquitectura clasicista, 454. Véase también Ferrero Maeso, Concepción. 1995. Francisco de Praves (1586-1637). [Valladolid]: Junta de Castilla y León. 
79 Ramallo Asensio explica este proceso en Ramallo Asensio, Germán. 1991. "Transformaciones morfológicas y de significado en la catedral de Oviedo durante los siglos del Barroco." In AA. V., Actas I Congreso Internacional do Barroco, 299-321. Porto: Reitoria de Universidade do Porto - Governo Civil do Porto.

80 La autoría de Naveda ha sido documentada por vez primera por Ramallo Asensio (Ramallo Asensio, La arquitectura civil, 103-104). Véanse también sus análisis en Ramallo Asensio, "El Barroco", 16-17 y "El Barroco" (1999), 140-149. Por su parte, Losada Varea dio a conocer el contrato de obra en La arquitectura en el otoño, 289.

81 Sobre este asunto véase Gómez Martínez, Javier. 1998. El gótico español de la Edad Moderna. Bóvedas de crucería, 55 y 201. Valladolid: Universidad de Valladolid.

82 Para las reformas de la sacristía véase Madrid Álvarez, Vidal de la. 1998. El arquitecto barroco Francisco de la Riva Ladrón de Guevara (1686-1741), 148153. Gijón: Ediciones Trea.

83 Losada Varea, La arquitectura en el otoño, 299.

84 Ramallo Asensio, "El Barroco" (1999), 151. También Losada Varea, La arquitectura en el otoño, 296.

85 Losada Varea, La arquitectura en el otoño, 297. La preocupación de Naveda por la formación teórica ha quedado atestiguada con el conocimiento de parte de su biblioteca, que en 1614 ya contaba con volúmenes de Vitrubio, Alberti, Vignola y Serlio; véase Losada Varea, La arquitectura en el otoño, 54.

86 Esta obra fue atribuida a Juan de Naveda por el profesor Ramallo Asensio (Ramallo Asensio, "Arquitectura barroca religiosa", 233). Posteriormente, Francisco de Caso (Caso, "Algunos datos") y Yayoi Kawamura (Kawamura, "Reflexión") lo confirmaron documentalmente. Véase también Losada Varea, La arquitectura en el otoño, 298-310.

87 El profesor Ramallo Asensio fue el primero en identificar la relación de la capilla de la Anunciación con el panteón romano (Ramallo Asensio, "Arquitectura barroca religiosa", 234) y la profesora Kawamura confirmó esta hipótesis (Kawamura, "Reflexión").
88 Ramallo Asensio, "El Barroco" (1999), 162.

89 Losada Varea comenta también la inspiración viñolesca del retablo (Losada Varea, La arquitectura en el otoño, 308).

90 Sobre Ignacio de Cajigal véanse: Ramallo Asensio, La Arquitectura Civil, 115-119; Ramallo Asensio, «El Barroco», 26-27; Ramallo Asensio, Germán. 1986. "Aportaciones para el conocimiento de la persona y obra de Ignacio del Cajigal, arquitecto de la mitad del siglo XVII." Liño, n 6: 7-32; Ramallo Asensio, "Arquitectura Barroca Religiosa", 234-236; Ramallo Asensio, "El Barroco" (1999), 163-173; González Echegaray y otros, Artistas cántabros, 112-113; Madrid Álvarez, "Arquitectura barroca civil", 206-207; Madrid Álvarez, Vidal de la y Germán Ramallo Asensio. 1996. "Arquitectura barroca religiosa (II)". In Barón Thaidigsmann, El Arte en Asturias, 250-251; Madrid Álvarez, Vidal de la. 2009. El convento del Santísimo Sacramento y Purísima Concepción de Nuestra Señora de Agustinas Recoletas de Gijón (1668-1842), 43-59. Gijón: Ediciones Trea; Kawamura, Yayoi. 2004. "El claustro procesional del monasterio de San Pelayo de Oviedo, obra realizada por el arquitecto Ignacio de Cajigal." Studium Ovetense, $\mathrm{n}^{\circ}$ 32: 175-188 y Kawamura, Arquitectura y poderes civiles, 36-37, 58-59, 72-79, 126-140 y 188-197.

91 Sobre el ayuntamiento de Oviedo véanse Ramallo Asensio, Arquitectura civil, 103-113; Ramallo Asensio, "El Barroco", 17-19; Kawamura, Arquitectura y poderes civiles, 80-90 y 99-119 y Madrid Álvarez, Vidal de la. 2013. "El arquitecto Juan de Estrada y la persistencia del clasicismo en Asturias." BSAA arte, $n^{\circ}$ 79: 93-116.

92 Estas capillas han sido estudiadas por Predrayes Obaya, "La capilla de la Concepción", 10-14 y "El arquitecto Juan de Naveda", 61-68. También Losada Varea, La arquitectura en el otoño, 314-320.

93 Para la obra de Melchor de Velasco en Asturias deben consultarse: Ramallo Asensio, "El Barroco", 24-26; Ramallo Asensio, Germán. 1994. "El arquitecto Melchor de Velasco antes de su llegada a Galicia". In AA. VV., Tiempo y espacio en el Arte. Homenaje al profesor Antonio Bonet Correa, 501-523. Madrid: Universidad Complutense de Madrid; González Echegaray y otros, Artistas cántabros, 687-688; González Santos, Javier. 1996. La Casa de OviedoPortal. Oviedo: Museo de Bellas Artes de Asturias; Madrid Álvarez y Ramallo Asensio, "Arquitectura barroca religiosa (II)", 247-250; Cagigas Aberasturi, Aramburu-Zabala y Escallada González, Los maestros canteros, 218-227; Kawamura, "El claustro procesional"; Kawamura, Yayoi. 2005. "Proyecto de Melchor de Velasco para el monasterio de San Pelayo de Oviedo." Liño, n 11: 93102; Kawamura, Yayoi. 2005. "Melchor de Velasco, tracista de la ampliación barroca del Monasterio de San Vicente de Oviedo." BSAA arte, n 71: 193-214; Kawamura, Yayoi. 2006. "Traída de agua para el monasterio de Santa María de la Vega de Oviedo, proyecto del arquitecto Melchor de Velasco." Liño, $n^{\circ}$ 12: 89-97; Kawamura, Arquitectura y poderes civiles, 33-35, 67-72 y 90-99; Sanz Fuentes, María Josefa y María José Buría Fernández. 2002. "El arquitecto Melchor de Velasco y el claustro del monasterio de Obona." De Arte, $\mathrm{n}^{\circ} 1$ : 81-88.

${ }^{94}$ Sobre las casas consistoriales de Avilés véanse Ramallo Asensio, La arquitectura civil, 110-113; Ramallo Asensio, "El Barroco", 27; Madrid Álvarez, "Arquitectura barroca civil", 204-206 y Madrid Álvarez, "El arquitecto Juan de Estrada", 106-116.

95 Madrid Álvarez, "El arquitecto Juan de Estrada", 99-107.

96 Acerca de Gregorio de la Roza véanse Ramallo Asensio, La arquitectura civil, 128-133; Ramallo Asensio, "El Barroco", 29-32; Cagigas Aberasturi, Aramburu-Zabala y Escallada González, Los maestros canteros, 227-232; Cofiño Fernández, Isabel. 2004. Arquitectura religiosa en Cantabria 1685-1754, 160163. Santander: Universidad de Cantabria y Parlamento de Cantabria. Sobre la sala capitular de Santilla del Mar véase Gómez Martínez, Javier. 1998. "Adiciones barrocas a la colegiata de Santillana del Mar", Altamira, n 53: 125-148.

97 "La capilla, en líneas generales, se clasifica dentro de la órbita del clasicismo posherreriano difundido en el 
norte de España por los maestros trasmeranos", Kawamura, Yayoi. 2004. "Capilla de San Pedro en el valle de Rozadas, Villaviciosa. Obra de Gregorio de la Roza, promovida por Santos de San Pedro", BRIDEA, n 164: 248.

98 Acerca de las casas de Malleza en Oviedo deben consultarse Ramallo Asensio, La arquitectura civil, 128-132; Ramallo Asensio, "El Barroco", 30-31; Madrid Álvarez, "Arquitectura barroca civil", 210-211; Kawamura, Yayoi. 2003. "Precisiones sobre la construcción de la casa palacio de Fernando de Malleza y Dóriga en Oviedo", BRIDEA, n 161: 161-171.

99 Acerca de los Menéndez Camina deben consultarse Ramallo Asensio, Germán. 1979. "El decorativismo en la arquitectura barroca asturiana. Los Menéndez Camina." In AA. VV., I Semana del Patrimonio Artístico Asturiano, 83103. Gijón: Caja de Ahorros de Asturias; Ramallo Asensio, "El Barroco", 33-35 y Madrid Álvarez, Los Menéndez Camina.

${ }^{100}$ La capilla de Santa Eulalia de la catedral de Oviedo ha sido estudiada en Ramallo Asensio, "El decorativismo"; Ramallo Asensio, "El Barroco" (1999), 174-181; Madrid Álvarez, Vidal de la. 2008. "El obispo fray Simón García Pedrejón y la capilla de Santa Eulalia de Mérida en la catedral de Oviedo (16901696). Nuevas Aportaciones." Liño, $n^{\circ}$ 14: 35-54 y Madrid Álvarez, Los Menéndez Camina, 130-156.

${ }^{101}$ El palacio del marqués de Camposagrado de Avilés ha sido analizado en Ramallo Asensio, La arquitectura civil, 133-140; Ramallo Asensio, "El Barroco", 35; Ramallo Asensio, "Las casas urbanas"; Madrid Álvarez, "Arquitectura barroca civil", 215-217; Madrid Álvarez, "El palacio del marqués" y Madrid Álvarez, Los Menéndez Camina, 156178.

102 Madrid Álvarez, Los Menéndez Camina, 211-222.

${ }^{103}$ La vinculación estructural entre las casas consistoriales de Avilés y la vivienda de Rodrigo García Pumarino fue apuntada por vez primera por el profesor Ramallo (Ramallo Asensio, La arquitectura civil, 126). Sobre esta obra véanse también [Rodríguez Vega, Sabina]. 1989. "Cine Marta y María (antigua casa de García Pumarino)". In Madrid Álvarez, Vidal (coord.), El patrimonio artístico de Avilés, 245-247. Avilés: Casa Municipal de Cultura de Avilés; Madrid Álvarez, "Arquitectura barroca civil", 217-219 y Madrid Álvarez, Los Menéndez Camina, 226-235.

104 Samaniego Burgos, José A. 1979. "Monumentos". In AA. VV., El Libro de Gijón, 234, Gijón: Naranco; Ramallo Asensio, "El Barroco", 39-40; Madrid Álvarez, Vidal de la. 1992. Palacio Revillagigedo y Colegiata de San Juan Bautista. Oviedo: Caja de Ahorros de Asturias; Madrid Álvarez, "Arquitectura civil barroca", 219-222 y Madrid Álvarez, Los Menéndez Camina, 235258.

${ }^{105}$ Ramallo Asensio, Germán. 1976. "Documentación y estudio de la obra realizada por fray Pedro Martínez de Cardeña en el monasterio de San Pelayo, de Oviedo", BIDEA, n 87: 183204.

106 Sobre estos conventos agustinos véase Madrid Álvarez, El convento del Santísimo Sacramento.

107 Ramallo Asensio, "Documentación y estudio", 192-193.

108 Ramallo Asensio. "El Barroco", 40-41; Madrid Álvarez, Vidal de la. 1990. "La construcción de la capilla de Nuestra Señora del Rey Casto y Panteón Real de la catedral de Oviedo." Liño, $n^{\circ}$ 9: 77-107; Ramallo Asensio, "El Barroco" (1999), 181-195 y Madrid Álvarez, Vidal de la. 2010. "La Capilla Real de la catedral de Oviedo, Felipe V y la Virgen de las Batallas: la creación de un instrumento de legitimación borbónica". In Ramallo Asensio, Germán (coord.), La catedral guía mental y espiritual de la Europa Barroca Católica, 511-548. Murcia: Universidad de Murcia.

${ }^{109}$ Acerca del pilar siloesco véase Rosenthal, Earl E. 1990. La catedral de Granada, 103-108. Granada: Universidad de Granada.

110 Sobre Pedro Antonio Menéndez y su obra del hospicio véanse Ramallo Asensio, La arquitectura civil, 192-198; Ramallo Asensio, "El Barroco", 45-46 y Madrid Álvarez, Vidal de la. 1997. Pedro Antonio Menéndez. Un arquitecto entre el Barroco y la llustración. Avilés: Azucel.
111 Acerca de Manuel Reguera y su obra pueden consultarse Llaguno, Eugenio y Juan Agustín Ceán Bermúdez. 1829. Noticias de los arquitectos y arquitectura de España desde su Restauración, t. IV, 319-321. Madrid: Imprenta Real; Ramallo Asensio, La arquitectura civil, 181-201; Madrid Álvarez, Vidal de la, La arquitectura de la llustración; Madrid Álvarez, Vidal de la. 1999. "Arquitectura de la llustración (I): Manuel Reguera". In Barón Thaidigsmann, Javier (dir.), El arte en Asturias a través de sus obras, 261-276. Oviedo: Prensa Asturiana y Madrid Álvarez, Vidal de la. 2007. "Manuel Reguera (Candás, 1731-Oviedo, 1798). In AA. VV., Artistas Asturianos. Arquitectos, 86-119. Oviedo: Hércules Astur de Ediciones.

${ }_{112}$ Madrid Álvarez, Vidal de la, La arquitectura de la llustración, 90.

${ }^{113}$ Madrid Álvarez, Vidal de la, La arquitectura de la llustración, 101-122 y Madrid Álvarez, Vidal de la. 2012. El palacio de Velarde. Oviedo: Museo de Bellas Artes de Asturias.

${ }^{114}$ Madrid Álvarez, Vidal de la. 1993. "El pórtico del convento de Santo Domingo de Oviedo. Una propuesta herreriana en el siglo XVIII." In AA. WV., Juan de Herrera y su influencia. Actas del Simposio, 261-266. Santander: Fundación Obra Pía Juan de Herrera y Universidad de Cantabria; Madrid Álvarez, Vidal de la, La arquitectura de la llustración, 122-130.

115 En este aspecto resulta muy reveladora la estampa de la portada de la edición española del Compendio de Vitruvio de Claudio Perrault, traducido por José Castañeda en 1761, donde se ilustra el monasterio de El Escorial y que sustituye a la lámina de la edición francesa, donde aparecían las obras más relevantes de Perrault. Véase Bérchez Gómez, Joaquín. 1981. "Estudio Introductorio." In Perrault, Claudio, Compendio de los diez libros de arquitectura de Vitruvio, VII-XCIV. Murcia: Colegio Oficial de Aparejadores y Arquitectos Técnicos, Galería-librería Yerba y Consejería del Cultura del Consejo Regional. 


\section{REFERENCIAS}

AA. WV. Herrera y el Clasicismo. Valladolid: Junta de Castilla y León, 1986.

AA. VV. Doña Magdalena de Ulloa, mujer de Luis Quixada (1598-1998). Una mujer de Villagarcía de Campos (Valladolid). Su profundo influjo social. Valladolid: Diputación de Valladolid, 1998

Abad, Camilo María. Doña Magdalena de Ulloa. La educadora de don Juan de Austria y fundadora del colegio de la Compañía de Jesús de Villagarcía de Campos (1525-1598). Comillas: Universidad Pontificia de Comillas, 1959.

Bérchez Gómez, Joaquín. "Estudio Introductorio." In Perrault, Claudio, Compendio de los diez libros de arquitectura de Vitruvio, VIIXCIV. Murcia: Colegio Oficial de Aparejadores y Arquitectos Técnicos, Galería-librería Yerba y Consejería del Cultura del Consejo Regional, 1981.

Bonet Correa, Antonio. La arquitectura en Galicia durante el siglo xvii. Madrid: CSIC, 1984 (reimpresión ed. Madrid, 1966).

Bustamante García, Agustín. La arquitectura clasicista del foco vallisoletano (1561-1640). VaIladolid: Institución Cultural Simancas, 1983.

Cadiñanos Bardeci, Inocencio. "Pompeyo Leoni y los arcos de la entrada triunfal de Doña Ana de Austria." Boletín de la Real Academia de Bellas Artes de San Fernando 86 (1998): 177-191.

Cagigas Aberasturi, Ana, Miguel Ángel Aramburu-Zabala Higuera y Luis de Escallada González. Los maestros canteros de Ribamontán. Ayuntamiento de Ribamontán al Mar y Ayuntamiento de Ribamontán al Monte, 2001.

Campos Sánchez-Bordona, María Dolores. "Los órdenes clásicos en la arquitectura de Juan del Ribero Rada." In AA. VV., Actas del X Congreso del CEHA. Los clasicismos en el arte español, 467-474. Madrid: UNED, 1994.

Campos Sánchez-Bordona, María Dolores. "Juan del Ribero Rada y el orden dórico." Academia 81 (1995): 517-541.

Campos Sánchez-Bordona, María Dolores. "Juan del Ribero Rada. Arquitecto clasicista." Altamira 52 (1996): 127-166.
Campos Sánchez-Bordona, María Dolores. "Arte y cultura en la biblioteca de Juan del Ribero Rada." In Nieto Ibáñez, Jesús María, Humanismo y Tradición Clásica en España y América, 311-332. León: Universidad de León. 2002

Campos Sánchez-Bordona, María Dolores. "Las transformaciones de la arquitectura señorial del renacimiento español, como reflejo del devenir histórico y del debate de las teorías restauradoras. El ejemplo del palacio de los Guzmanes de León." De Arte 6 (2007): 167194. https://doi.org/10.18002/da.v0i6.1535

Campos Sánchez-Bordona, María Dolores.. "Juan del Ribero Rada. Intérprete e impulsor del modelo clasicista en la arquitectura monástica benedictina." BSAA Arte 78 (2012): 19-44.

Canella Secades, Fermín. Historia de la Universidad de Oviedo y noticias de los establecimientos de enseñanza de su distrito (Asturias y León). Oviedo, 1903.

Caravita, Andrea. I codici e le arti a Monte Cassino, vol. III. Monte Cassino, 1871.

Casaseca Casasecja, Antonio. Rodrigo Gil de Hontañón (Rascafría 1500-Segovia 1577). Salamanca: Junta de Castilla y León, 1988.

Caso, Francisco de. "Algunos datos documentales sobre la capilla de los Vigiles y su retablo." Astura 11(2001): 57-65.

Ceán Bermúdez, Juan Agustín. Diccionario histórico de los más ilustres profesores de las Bellas Artes en España. Madrid: Real Academia de San Fernando, 1800.

Cofiño Fernández, Isabel. Arquitectura religiosa en Cantabria 1685-1754. Santander: Universidad de Cantabria y Parlamento de Cantabria, 2004.

Cruz Valdovinos, José Manuel. "La entrada de la reina Ana en Madrid en 1570." Anales del Instituto de Estudios Madrileños 28 (1990): 413-452.

Cuervo, Justo. "El monasterio de San Juan de Corias." In Bellmunt y Traver, Octavio y Fermín Canella y Secades, Asturias, t. I, 225-238. Gijón, 1894.

Díaz Álvarez, Juan. "La obra del arquitecto Juan de Naveda o la recepción del Clasicismo Herre- 
riano en la Asturias del primer tercio del siglo XVII." In Llordén Miñambres, Moisés y Juan Miguel Menéndez Llana, coords., I Congreso de Estudios Asturianos, vol. 5, 31-49. Oviedo: RIDEA, 2007.

Díaz Álvarez, Juan. "Arquitectura manierista asturiana: el Palacio Valdés de Gijón." Liño 18 (2012): 43-55.

Estella Marcos, Margarita. Juan Bautista Vázquez el viejo en Castilla y América. Madrid: CSIC, 1990.

Faya Díaz, María Ángeles. "Los Valdés Salas y la fundación de la Universidad de Oviedo." In Faya Díaz, María Ángeles, coord., La nobleza en la Asturias del Antiguo Régimen, 147-197. Oviedo: KRK Ediciones, 2004.

Faya Díaz, María Ángeles. "La fundación de la Universidad. Las memorias y obras pías del arzobispo Fernando de Valdés y sus vicisitudes." In Uría, Jorge, Carmen García y Aida Terrón, eds., Historia de la Universidad de Oviedo, vol. I, 35-81 y 255-273. Oviedo: Universidad de Oviedo, 2008.

Fernández Conde, Javier. "Centralismo y reforma en los monasterios benedictinos asturianos a finales de la Edad Media: Implantación de la Congregación de la Observancia de San Benito de Valladolid." Aragón en la Edad Media 1415 (1999): 509-520.

Fernández del Hoyo, María Antonia.. "Juan del Ribero y la iglesia monasterial de San Vicente de Oviedo." Astura 1 (1983): 69-70.

Fernández Martín, Luis. “Domingo de Argos, constructor de la iglesia de San Juan de Corias." Astura 4 (1985): 79-83.

Ferrero Maeso, Concepción. Francisco de Praves (1586-1637). [Valladolid]: Junta de Castilla y León, 1995.

Ferro Couselo, Jesús. "Las obras del colegio e iglesia de Montederramo en los siglos xvi y xvii." Boletín Auriense 1 (1971): 145-186.

García Álvarez-Busto, Alejandro. Arqueología de la arquitectura monástica en Asturias: San Juan Bautista de Corias. Oviedo: Consejería de Educación y Cultura del Principado de Asturias, 2016.
García Cuetos, María Pilar. Arquitectura en Asturias, 1500-1580. La dinastía de los Cerecedo. Oviedo: Real Instituto de Estudios Asturianos, 1996.

García Oro, José. "Conventualismo y observancia." In García-Villoslada, Ricardo, dir., Historia de la Iglesia en España, vol. 3, t. 1, 211-350. Madrid: BAC, 1979.

García Sánchez, Justo. Los jesuitas en Asturias. Oviedo: IDEA, 1991.

Gómez Martínez, Javier. El gótico español de la Edad Moderna. Bóvedas de crucería. Valladolid: Universidad de Valladolid, 1998.

Gómez Martínez, Javier. "Adiciones barrocas a la colegiata de Santillana del Mar." Altamira 53 (1998): 125-148.

González Carvajal, Tomás. Registro y relación general de minas de la corona de Castilla. Primera parte. Comprende los registros, relaciones $y$ despachos tocantes a minas, en que se expresan los pueblos y sitios en que se hallaron. [Madrid], 1832

González Echegaray, María del Carmen, Miguel Ángel Aramburu-Zabala Higuera, Begoña Alonso Ruiz y Julio J. Polo Sánchez. Artistas cántabros de la Edad Moderna. Su aportación al arte hispánico. [Santander]: Institución Mazarrasa y Universidad de Cantabria, 1991.

González Novalín, José Luis. El Inquisidor General Fernando de Valdés (1483-1568), 2 vols. Oviedo: Universidad de Oviedo, 1971.

González Sánchez, Irma. "Patrimonio económico de la nobleza en el Gijón del siglo XVIII." In Faya Díaz, María Ángeles, coord., La nobleza en la Asturias del Antiguo Régimen, 199-220. Oviedo: KRK Ediciones, 2004.

González Sánchez, Irma.. Los Valdés, una casa nobiliaria en el Gijón de los siglos XVI y XVII. Oviedo: KRK Ediciones, 2009.

González Santos, Javier.. “El escultor florentino Juan Bautista Portigiani. Noticias de sus obras en Asturias." BSAA 52 (1986): 297-310.

González Santos, Javier. La Casa de Oviedo-Portal. Oviedo: Museo de Bellas Artes de Asturias, 1996. 
González Santos, Javier. "Les Artes n'Asturies en tiempo d'Anton de Marirreguera." In AA. VV., Anton de Marirreguera y el Barrocu Asturianu, 91-113. Oviedo: Principado de Asturias. 2000.

Hoag, John D. Rodrigo Gil de Hontañón. Gótico y Renacimiento en la arquitectura española del siglo XVI. Madrid: Xarait Ediciones, 1985.

Kawamura, Yayoi. "Precisiones sobre la construcción de la casa palacio de Fernando de Malleza y Dóriga en Oviedo." BRIDEA 161 (2003): 161-171.

Kawamura, Yayoi. "Reflexión sobre el modelo del Panteón de Roma en la capilla del obispo Vigil de la catedral de Oviedo y otras precisiones." BSAA 69-70 (2003-2004): 359-372.

Kawamura, Yayoi. "Capilla de San Pedro en el valle de Rozadas, Villaviciosa. Obra de Gregorio de la Roza, promovida por Santos de San Pedro." BRIDEA 164 (2004): 241-260.

Kawamura, Yayoi. "El claustro procesional del monasterio de San Pelayo de Oviedo, obra realizada por el arquitecto Ignacio de Cajigal." Studium Ovetense 32 (2004): 175-188.

Kawamura, Yayoi. "Proyecto de Melchor de Velasco para el monasterio de San Pelayo de Oviedo." Liño 11 (2005): 93-102.

Kawamura, Yayoi. 2006. Arquitectura y poderes civiles. Oviedo 1600-1680. Oviedo: RIDEA.

Kawamura, Yayoi. "Traída de agua para el monasterio de Santa María de la Vega de Oviedo, proyecto del arquitecto Melchor de Velasco." Liño 12 (2006): 89-97.

Kawamura, Yayoi. "El arquitecto Domingo de Mortera: acerca de su biblioteca y sus últimos trabajos." BSAA Arte 76 (2010): 71-80.

Losada Varea, Celestina. La arquitectura en el otoño del Renacimiento. Juan de Naveda. Santander: Universidad de Cantabria, 2007.

Llaguno y Amirola, Eugenio, y Juan Agustín Ceán Bermúdez. Noticias de los arquitectos y arquitectura de España desde su Restauración. Madrid: Imprenta Real, 1829.

Madrid Álvarez, Vidal de la. "La construcción de la capilla de Nuestra Señora del Rey Casto y
Panteón Real de la catedral de Oviedo." Liño 9 (1990): 77-107.

Madrid Álvarez, Vidal de la. Palacio Revillagigedo y Colegiata de San Juan Bautista. Oviedo: Caja de Ahorros de Asturias, 1992.

Madrid Álvarez, Vidal de la. "El pórtico del convento de Santo Domingo de Oviedo. Una propuesta herreriana en el siglo XVIII." In AA. W., Juan de Herrera y su influencia. Actas del Simposio, 261-266. Santander: Fundación Obra Pía Juan de Herrera y Universidad de Cantabria, 1993.

Madrid Álvarez, Vidal de la. "Arquitectura barroca civil." In Barón Thaidigsmann, Javier, dir., El arte en Asturias a través de sus obras, 197228. Oviedo: Prensa Asturiana, 1996.

Madrid Álvarez, Vidal de la. Pedro Antonio Menéndez. Un arquitecto entre el Barroco y la Ilustración. Avilés: Azucel, 1997.

Madrid Álvarez, Vidal de la. El arquitecto barroco Francisco de la Riva Ladrón de Guevara (16861741). Gijón: Ediciones Trea, 1998.

Madrid Álvarez, Vidal de la. "Arquitectura de la llustración (I): Manuel Reguera." In Barón Thaidigsmann, Javier, dir., El arte en Asturias a través de sus obras, 261-276. Oviedo: Prensa Asturiana, 1999.

Madrid Álvarez, Vidal de la. "Arte y mecenazgo indiano en la Asturias del Antiguo Régimen." In Sazatornil Ruiz, Luis, ed., Arte y mecenazgo indiano. Del Cantábrico al Caribe, 317-348. Gijón: Ediciones Trea, 2007.

Madrid Álvarez, Vidal de la. "Manuel Reguera (Candás, 1731-Oviedo, 1798)." In AA. VV., Artistas Asturianos. Arquitectos, 86-119. Oviedo: Hércules Astur de Ediciones, 2007.

Madrid Álvarez, Vidal de la. "El obispo fray Simón García Pedrejón y la capilla de Santa Eulalia de Mérida en la catedral de Oviedo (1690-1696). Nuevas Aportaciones." Liño 14 (2008): 35-54.

Madrid Álvarez, Vidal de la. El convento del Santísimo Sacramento y Purísima Concepción de Nuestra Señora de Agustinas Recoletas de Gijón (1668-1842). Gijón: Ediciones Trea, 2009.

Madrid Álvarez, Vidal de la. "El palacio del marqués de Camposagrado en Avilés (Asturias) y 
la muralla de la villa a finales del siglo XVII." Liño 16 (2010): 67-83.

Madrid Álvarez, Vidal de la. "La Capilla Real de la catedral de Oviedo, Felipe $V$ y la Virgen de las Batallas: la creación de un instrumento de legitimación borbónica." In Ramallo Asensio, Germán, coord., La catedral guía mental y espiritual de la Europa Barroca Católica, 511548. Murcia: Universidad de Murcia, 2010.

Madrid Álvarez, Vidal de la. El palacio de Velarde. Oviedo: Museo de Bellas Artes de Asturias, 2012.

Madrid Álvarez, Vidal de la. "El arquitecto Juan de Estrada y la persistencia del clasicismo en Asturias." BSAA Arte 79 (2013): 93-116.

Madrid Álvarez, Vidal de la. Los Menéndez Camina y la arquitectura barroca en Asturias. Gijón: Trea, 2018.

Madrid Álvarez, Vidal de la, y Germán Ramallo Asensio. "Arquitectura barroca religiosa (II)." In Barón Thaidigsmann, El arte en Asturias a través de sus obras, 245-260. Oviedo: Prensa Asturiana, 1996.

Marías, Fernando. La arquitectura del Renacimiento en Toledo (1541-1631). Toledo: Instituto Provincial de Investigaciones y Estudios Toledanos, 1983.

Marías, Fernando. El largo siglo XVI. Madrid: Taurus, 1989.

Marías, Fernando. "Los sintagmas clásicos en la arquitectura española del siglo XVI." In AA. W., L'emploi des ordres dans I'architecture de la Renaissance, 247-261. París: Picard, 1992.

Marías, Fernando. "Nicolás de Vergara el viejo y la lámpara de plata del Escorial." In Cañestro Donoso, Alejandro, coord., Scripta artivm in honorem Prof. José Manuel Cruz Valdovinos, 163-178. Alicante: Universidad de Alicante, 2018.

Miguel Vigil, Ciriaco. Colección Histórico-Diplomática del Ayuntamiento de Oviedo. Oviedo, 1889.

Morales Saro, María Cruz. "Datos sobre la construcción del monasterio de Corias (Cangas del Narcea)." Boletín del Instituto de Estudios Asturianos 93-94 (1978): 295-313.
Muñoz Jiménez, José Miguel. "Juan de Naveda y la arquitectura del manierismo clasicista en la villa de Santander (1600-1630)." Altamira 45 (1985): 189-210.

Muñoz Jiménez, José Miguel. "Reflexiones sobre la significación del arquitecto Juan de Naveda (1607-1640)." Historias de Cantabria 2 (1992): 7-21.

Muñoz Jiménez, José Miguel. "Juan del Ribero Rada (1540-1600), arquitecto palladiano y antiherreriano." Historias de Cantabria 6 (1993): 24-62.

Palladio, Andrea. Los cuatro libros de Arquitectura de Andrea Palladio, traducidos del italiano al castellano por Juan del Ribero Rada, estudio introductorio, edición y notas de María Dolores Campos Sánchez-Bordona. Salamanca: Junta de Castilla y León y Universidad de León, 2003.

Parada López de Corselas, Manuel. "La serliana del palacio de Carlos V en Granada: Arquitectura del poder entre España e Italia." In Galera, Pedro A. y Sabine Frommel (eds.), El patio circular en la arquitectura del Renacimiento. De la casa de Mantegna al palacio de Carlos V, 151-192. Sevilla: Universidad Internacional de Andalucía, 2018.

Pastor Criado, María Isabel. Arquitectura purista en Asturias. Oviedo, Principado de Asturias, 1987.

Pastor Criado, María Isabel. "Las vías de penetración del purismo clasicista en Asturias y su proyección." Príncipe de Viana. Anejo 12 (1991): 258.

Pastor Criado, Isabel. "Arquitectura de la segunda mitad del siglo XVI." In Barón Thaidigsmann, Javier, El arte en Asturias a través de sus obras, 181-196. Oviedo: Prensa Asturiana, 1996.

Patac, José María, y Elviro Martínez. Historia del Colegio de San Matías de Oviedo. Gijón: Biblioteca Asturiana, 1991 (2 edición corregida y aumentada de la 1976).

Pedrayes Obaya, Juan José. "La capilla de la Concepción de Villaviciosa: una obra desconocida de Juan de Naveda." Boletín Académico 12 (1990): 10-14. 
Pedrayes Obaya, Juan José. "El arquitecto Juan de Naveda y la capilla de los Reyes Magos del Palacio de Villabona." Astura 10 (1996): 61-68.

Pérez Sedano, Francisco. Datos documentales inéditos para la Historia del Arte Español I. Notas del archivo de la catedral de Toledo, redactadas sistemáticamente, en el siglo XVIII, por el canónigo-obrero don ... Madrid, 1914.

Quadrado, José María. Recuerdos y Bellezas de España. Asturias y León. Madrid, 1855.

Ramallo Asensio, Germán. “Documentación y estudio de la obra realizada por fray Pedro Martínez de Cardeña en el monasterio de San Pelayo, de Oviedo." BIDEA 87 (1976): 183204.

Ramallo Asensio, Germán. La arquitectura civil asturiana (Época Moderna). Salinas: Ayalga Ediciones, 1978.

Ramallo Asensio, Germán. "El decorativismo en la arquitectura barroca asturiana. Los Menéndez Camina." In AA. VV., I Semana del Patrimonio Artístico Asturiano, 83-103. Gijón: Caja de Ahorros de Asturias, 1979.

Ramallo Asensio, Germán. "El Renacimiento." In AA. VV., Arte Asturiano II (del Barroco a la actualidad), 313-344. Gijón: Silverio Cañada, 1981.

Ramallo Asensio, Germán. "El Barroco." In AA. V., Arte Asturiano II (del Barroco a la actualidad), 13-86. Gijón: Silverio Cañada, 1981.

Ramallo Asensio, Germán.. “La zona suroccidental asturiana: Tineo, Cangas del Narcea, Allande, Ibias y Degaña." Liño 2 (1981): 185-271.

Ramallo Asensio, Germán. "Los monasterios benedictinos como promotores de la evolución artística en Asturias." In AA. VV., Semana de historia del monacato cántabro-astur-leonés, 421-453. Oviedo: Monasterio de San Pelayo, 1982.

Ramallo Asensio, Germán. "Las casas urbanas de la familia Camposagrado." In AA. WV., II Simposio sobre el padre Feijoo y su siglo, t. II, 575-592. Oviedo: Centro de Estudios del siglo XVIII, 1983.

Ramallo Asensio, Germán. "Aportaciones para el conocimiento de la persona y obra de Ignacio del Cajigal, arquitecto de la mitad del siglo XVII." Liño 6 (1986): 7-32.

Ramallo Asensio, Germán. "Transformaciones morfológicas y de significado en la catedral de Oviedo durante los siglos del Barroco." In AA. V., Actas I Congreso Internacional do BarroCo, 299-321. Porto: Reitoria de Universidade do Porto - Governo Civil do Porto, 1991.

Ramallo Asensio, Germán. "El particular caso de las capillas palaciegaen la arquitectura barroca asturiana." In AA. VV., Actas VII CEHA, 359372. Murcia: Universidad de Murcia, 1992.

Ramallo Asensio, Germán. "El palacio urbano en Asturias." In Ramallo Asensio, Germán, coord., Arquitectura señorial en el norte de España, 81-107. Oviedo: Universidad de Oviedo, 1993.

Ramallo Asensio, Germán. "El arquitecto Melchor de Velasco antes de su llegada a Galicia." In AA. VV., Tiempo y espacio en el Arte. Homenaje al profesor Antonio Bonet Correa, 501-523. Madrid: Universidad Complutense de Madrid, 1994.

Ramallo Asensio, Germán. "Una base de mesura y dignidad arquitectónicas." In Madrid Álvarez, Vidal de la, La arquitectura de la Ilustración en Asturias. Manuel Reguera 1731-1798, 13-17. Oviedo: Real Instituto de Estudios Asturianos, 1995.

Ramallo Asensio, Germán. "Arquitectura Barroca Religiosa (i): La catedral de Oviedo." In Barón Thaidigsmann, Javier, dir., El arte en Asturias a través de sus obras, 229-244. Oviedo: Editorial Prensa Asturiana, 1996.

Ramallo Asensio, Germán. "El Barroco." In Caso, Francisco de, Cosme Cuenca, César García de Castro, Jorge Hevia, Vidal de la Madrid y Germán Ramallo, La Catedral de Oviedo I. Historia y restauración, 140-163. Oviedo: Nobel, 1999.

Rivera Blanco, Javier. La arquitectura de la segunda mitad del siglo XVI en la ciudad de León. León: Institución "Fray Bernardino de Sahagún" y Consejo Superior de Investigaciones Científicas, 1982.

Rivera, Javier, coord. Monasterio de San Benito el Real de Valladolid VI Centenario 1390-1990. Valladolid: Ayuntamiento de Valladolid, INEM 
y Escuela-taller Monasterio de San Benito, 1990.

Rodríguez G. de Ceballos, Alfonso. "Juan de Herrera y los jesuitas Villalpando, Valeriani, Ruiz, Tolosa." Archivum Historicum Societatis lesu 35 (1966): 285-321.

Rodríguez G. de Ceballos, Alfonso. "La librería del arquitecto Juan del Ribero Rada." Academia 62 (1986): 121-154.

Rodríguez G. de Ceballos, Alfonso, y Antonio Casaseca. "Juan del Ribero Rada y la introducción del clasicismo en Salamanca y Zamora." In AA. V., Herrera y el Clasicismo, 95-109. Valladolid: Junta de Castilla y León, 1986.

Rodríguez Vega, Sabina. "Cine Marta y María (antigua casa de García Pumarino)." In Madrid Álvarez, Vidal, coord., El patrimonio artístico de Avilés, 245-247. Avilés: Casa Municipal de Cultura de Avilés, 1989.

Rosenthal, Earl E. La catedral de Granada. Granada: Universidad de Granada, 1990.

Sambricio, Carlos. "La fortuna de Sebastiano Serlio." In Serlio de Bolonia, Sebastián, Todas las obras de arquitectura y perspectiva de ..., 7-135. Oviedo: Colegio Oficial de Aparejadores y Arquitectos Técnicos de Asturias, 1986.

Sampedro Redondo, Laura. "Sobre la autoría del palacio de los Valdés en Gijón: de Juan de Cerecedo, el viejo, a Juan Bautista Portigiani." De Arte 4 (2005): 55-62. https://doi. org/10.18002/da.v0i4.1569

Sanz Fuentes, María Josefa, y María José Buría Fernández. "El arquitecto Melchor de Velasco y el claustro del monasterio de Obo- na." De Arte 1 (2002): 81-88. https://doi. org/10.18002/da.v0i1.1621

Selgas, Fortunato de. "Breves indicaciones sobre la arquitectura en Asturias." Revista de Asturias 16 (1880): 247-251.

Selgas, Fortunato de. "La arquitectura grecoromana en Asturias." Revista de Asturias 2 (1882): 17-23.

Simoncini, Giorgio. La memoria del medioevo: nell'architettura dei secoli XV-XVIII. Roma: Gangemi Editore, 2016.

Trelles Villademoros, José Manuel. Asturias Ilustrada. Primitivo origen de la nobleza en España, su antigüedad, clases, y diferencias, con la descendencia sucesiva de las principales familias del reyno, t. III. Madrid, 1760.

Velázquez Soriano, Isabel, Consuelo Gómez López, Antonio Espigares Pinilla y Ana Jiménez Garnica. La relación de la entrada triunfal de Ana de Austria en Madrid de Juan López de Hoyos. Estudios, edición, crítica y notas. Madrid: Universidad Complutense de Madrid, 2007.

Villafañe, Juan de. La Limosnera de Dios. Relación histórica de la vida, y virtudes de la excelentísima señora Doña Magdalena de Ulloa Toledo Ossorio y Quiñones, mujer del Excelentíssimo señor Luis Méndez Quixada Manuel de Figueredo y Mendoza. Salamanca, [1723].

Yepes, Antonio de. Coronica General de la Orden de San Benito, Patriarca de Religiosos. Universidad de Nuestra Señora de Irache, 1610. 
